\title{
Article \\ Quantitative Assessment of Chirality of Protein Secondary Structures and Phenylalanine Peptide Nanotubes
}

\author{
Alla Sidorova ${ }^{1, *}$, Vladimir Bystrov ${ }^{2}{ }^{\mathbb{D}}$, Aleksey Lutsenko ${ }^{1}$, Denis Shpigun ${ }^{1}$, Ekaterina Belova ${ }^{1} \mathbb{D}$ \\ and Ilya Likhachev ${ }^{2}$ \\ 1 Faculty of Physics, Lomonosov Moscow State University, 119991 Moscow, Russia; \\ aleksluchrus@yandex.ru (A.L.); denish.den@mail.ru (D.S.); ev.malyshko@physics.msu.ru (E.B.) \\ 2 Institute of Mathematical Problems of Biology, The Branch of Keldysh Institute of Applied Mathematics, RAS, \\ 142290 Pushchino, Russia; vsbys@mail.ru (V.B.); ilya_lihachev@mail.ru (I.L.) \\ * Correspondence: sky314bone@mail.ru
}

Citation: Sidorova, A.; Bystrov, V.;

Lutsenko, A.; Shpigun, D.; Belova, E.;

Likhachev, I. Quantitative

Assessment of Chirality of Protein

Secondary Structures and

Phenylalanine Peptide Nanotubes.

Nanomaterials 2021, 11, 3299. https://

doi.org/10.3390/nano11123299

Academic Editor: Eunji Lee

Received: 30 October 2021

Accepted: 2 December 2021

Published: 5 December 2021

Publisher's Note: MDPI stays neutral with regard to jurisdictional claims in published maps and institutional affiliations.

Copyright: (c) 2021 by the authors. Licensee MDPI, Basel, Switzerland. This article is an open access article distributed under the terms and conditions of the Creative Commons Attribution (CC BY) license (https:// creativecommons.org/licenses/by/ $4.0 /)$.

\begin{abstract}
In this study we consider the features of spatial-structure formation in proteins and their application in bioengineering. Methods for the quantitative assessment of the chirality of regular helical and irregular structures of proteins are presented. The features of self-assembly of phenylalanine (F) into peptide nanotubes (PNT), which form helices of different chirality, are also analyzed. A method is proposed for calculating the magnitude and sign of the chirality of helix-like peptide nanotubes using a sequence of vectors for the dipole moments of individual peptides.
\end{abstract}

Keywords: helical structures; peptide nanotubes; phenylalanine; self-assembly; molecular modeling; dipole moments; polarization; chirality; protein secondary structure

\section{Introduction}

There exists a sophisticated understanding of the relationship between amino acid sequences and the structure of various types of protein elements. This understanding has expanded the possibilities of managing the assembly of both natural proteins and artificial structures in the field of protein engineering, materials science, etc. Due to the biocompatibility of molecular recognition properties and availability for production, biomolecular nanostructures are attractive for use in various fields of biomedicine, biotechnology, and bioengineering. Artificial peptides, such as natural ones, can be targeted for self-assembly to perform a specific function. For example, some of the earliest artificially created peptides in tissue engineering demonstrated that self-organizing peptides are capable of supporting cell attachment and proliferation [1,2]. Other studies have shown that the use of peptides can promote the regeneration of axons and restoration of the brain of animals [3], cultivation of stem cells [4], coordination of lanthanide ions [5] and DNA binding [6]. Peptide nanotubes allow numerous chemical modifications and assist in exploiting the specificity of biological systems. For example, they are used to study the ability of very short aromatic peptides to form ordered amyloid fibrils, which have similar biophysical and structural properties and are a hallmark of a diverse group of diseases (Alzheimer's disease, type 2 diabetes, prion diseases). The spatial structure and forces of interaction of aromatic fragments provide the direction and energy necessary for these ordered structures' formation [7]. Therefore, many works studies have been conducted to study the three-dimensional structure of proteins in the context of determining the structural and functional features of regular and irregular protein secondary structures.

Chirality occupies a valuable space in studies of artificial structures, as it is used as a control characteristic of stratification in hierarchies of biomacromolecule structures and, as a consequence, their functional features [8,9]. During the formation of complex protein structures, a chirality sign alternation was identified, from left-handed (L) to right-handed (D), and during the transition between hierarchical levels. However, this pattern requires 
confirmation in the form of a qualitative and quantitative assessment of chirality for various protein structural levels.

One of the main objectives of protein engineering is to improve protein stability, and this task is associated with the chirality of protein structures. Syndiotactic chains have an enormous ensemble of available conformations; therefore, L- and D-amino acids are often used in bioengineering [10]. Heterochirality is not a characteristic feature of most biological systems. Homochiral amino acid chains, which have significantly fewer possible conformations than heterochiral ones, promote the formation of regular secondary structures since protein isotacticity reduces the entropic component of folding and, accordingly, increases the stability of protein structures [11]. Amino acids of different chirality have different effects on the self-assembly of proteins, and the substitution of enantiomers can alter the kinetics, morphology, and the mechanical properties of self-assembly of the peptides [12-21]. Thus, a substitution for a D-amino acid is able to disrupt the structure of the helix or $\beta$-sheet and destabilize the process of peptide self-assembly [22-25].

In [26,27], a new self-assembly mode based on the use of helical peptides with a chiral center, where chirality determines the self-assembly of helical structures, is proposed.

A study of the effect of the chirality of amino acids on the structures of diphenylalanine (FF) and its derivatives showed that switching the chirality of one Phe in FF derivatives changed the morphology of their self-assembly but retained the ability to self-assemble into nanotubes, and heterochirality made nanotubes more stable $[13,28,29]$. At the same time, it was shown that the hydrogel formed by the racemic ferrocene-diphenylalanine mixture was mechanically weaker than the enantiopure hydrogels [30]. Thus, there are differences in self-assembly between racemic mixtures and pure enantiomers. The introduction of D-amino acids into self-organizing L-peptides is widely used to increase the enzymatic stability of structures and affect their biological functions [19].

The left-handed helix of polyproline II (PPII) belongs to the trans-isomers (steric more favorable) of peptide bonds, and the more compact right-handed helix of polyproline I (PPI) belongs to the cis isomers. PPII helices are involved in signal transduction and in the assembly of the protein complex, transcription, protein self-assembly and elasticity, the regulation of many intracellular signaling complexes, and they play a significant structural role in amyloidogenic proteins [31,32].

The formation of sign-alternating chiral structures of different scales can also be observed in cholesteric liquid crystals formed by chiral molecules. In each layer, the molecules are predominantly oriented along the director, and upon passing to the neighbouring layer, the director rotates around the cholesteric axis (rotation is associated with stereospecific molecular restrictions). A helix is formed that is opposite in sign to the chirality of the molecules. "Left" cholesterol defines the dextrorotation of the director [33]. In the cholesteric phase of DNA, a change in the sign of chirality is also observed during the transition to the next level of organization [34]. The cholesteric phase comprises a standard organized parallel layers of DNA molecules. Each layer is rotated relative to the previous layer by a small angle. Right-handed DNA forms layers, which in turn form a left-handed helix.

The combination of flexibility and rigidity within one protein molecule is possibly associated with the aperiodicity of the protein structure crystals [35]. Orientational symmetry is broken in the aperiodic arrangement of secondary structural elements, and the folded structures are nematic droplets. At certain values of the introduced nematic order parameter $\mathrm{P}_{2}$, the arrangement of structural elements can withstand mechanical forces. This approach is found to be valid when considering the relationship between the three-dimensional organization and the nematic order of protein allostery.

In this article, we discuss methods for determining the chirality sign of regular (helical) and irregular (turns and loops) protein secondary structures, as well as the possibility of their application for helix-like peptide nanotubes based on amino acids. 


\section{Models and Computational Methods}

2.1. Objects of Study

\subsubsection{Protein Secondary Structures}

A particular manifestation of chirality is the helicity of structures. The helix boundaries are determined by a set of amino acids, the sequence of which is encoded in the DNA $[8,36]$. In this article, three types of regular secondary structures are considered $-\alpha, 3_{10}$, and $\pi$-helices.

$\alpha$-helices in natural proteins are more stable and resistant to mutations than $\beta$-sheets [37]. The most common protein-regular secondary structure is the right-handed $\alpha$-helix [38].

The third most common structures after $\alpha$-helices and $\beta$-sheets in globular proteins are $3_{10}$-helices [39]. These short helices are located at the sites of turns of $\alpha$-helices or their ends [40]. The $3_{10}$-helices have three residues per turn and are less-stable structures than $\alpha$-helices (possibly due to a slightly different structure of hydrogen bonds) [41]. Similar to $\alpha$-helices, $3_{10}$-helices are mainly observed in the right-handed conformation.

$\pi$-helices are formed as a result of the exclusion or addition of one amino acid residue in the $\alpha$-helix [42]; they are found in 15\% of protein structures [42] and, as a rule, are located near the functional sites of proteins [42]. Thus, $32 \%$ of 6 -residue $\pi$-helices are involved in ligand binding or constitute an active site, and $77 \%$ have conserved residues among homologous proteins [43]. The overwhelming majority of natural $\pi$-helices consist of seven residues and at least two consecutive $\pi$-type H-bonds [44].

Irregular secondary protein structures (turns and loops) act as a link between regular secondary structures [45] and are important elements of molecular recognition in protein folding [46]. The formation of irregular regions is largely determined by the primary amino acid sequence of the polypeptide chain [47]. Turns and coils account for approximately $30 \%$ [48] to $50 \%$ of the total secondary structure of globular proteins [49]. These structures are often present in the active sites of proteins, facilitating specific interactions between molecules [50] and, as a rule, are located on the surface of a globular protein.

Turns are sufficiently stable structures, since these isolated elements should actively promote the folding and maintenance of the globular form of the protein [51]. Depending on the number of residues separating the pair connected via the hydrogen bond, the turns are divided into $\delta-, \gamma-, \beta-, \alpha-$, and $\pi$-turns, consisting of 2 to 6 amino acid residues, respectively [52]. In this article, we consider such irregular secondary structures as $\beta$ - and $\alpha$-turns, and $\Omega$-loops.

For $\beta$ - and $\alpha$-turns, the distance between the first and last $\alpha$-carbons of the turn is less than $10 \AA$, and it has no hydrogen bond [52].

A $\beta$-turn (of 4 residues) is the most frequent type of turn [52], accounting for $63 \%$ of the residues in loops between regular secondary structures and around $25-30 \%$ of all protein residues [53]. Even for relatively small peptides, it is believed that the $\beta$-turn conformation is bioactive (the rate of $\beta$-turns formation is ten times lower than the rate of $\alpha$-helices formation) [54].

The $\alpha$-turn is not part of the $\alpha$-helix. Turns that are not hydrogen bonded contain more hydrophobic residues at $i$ and $i+4$ positions and can provide (and stabilize) hydrophobic interactions between turns. The most common structural motif with an $\alpha$-turn is a $\beta$-hairpin. According to the hypothesis, one of the mechanisms of $\alpha$-turn initiation is the development of an initial $\beta$-turn into an $\alpha$-turn [55]. The $\beta$-turn is important for understanding protein folding mechanisms.

$\Omega$-loops consist of 6-16 amino acid residues, where the lower limit of length serves to exclude reverse turns. As a rule, they are located on the surface of globular proteins, connect membrane $\alpha$-helices on the cytoplasmic or extracellular surface, and are often involved in recognition processes [56]. On average, a protein molecule contains around four $\Omega$-loops, the distance between the ends is less than the $\alpha$ - $\alpha$ carbon separation in a loop, the twisting angles of the main chain are not repeated, and there are fewer hydrogen bonds of the main chain [57]. The hydrogen bond in the main chain of the loop is irregular, which favors the packing of side chains within long loops [51]. Therefore, depending on 
the three-dimensional shape, $\Omega$-loops exhibit different degrees of flexibility during protein folding [58] and affect the function of protein structures [59]. Furthermore, $\Omega$-loops can be used in bioengineering since their replacement or elimination affects the stability and enzymatic activity of the protein.

It is clear that the identification of irregular structures in proteins is necessary for understanding their structure and functions since they connect secondary structural elements, change the direction of the polypeptide chain, and often contain residues of active sites.

\subsubsection{Peptide Nanotubes}

One example of the self-assembly of complex biomolecular structures is the formation of a helical nanotube-type structure based on a phenylalanine amino acid (F or Phe) [60]. It is known that, based on such a phenylalanine amino acid, dipeptides, diphenylalanine (FF or (Phe) $)_{2}$, are also formed, which are then easily assembled into peptide nanotubes [61-63]. Diphenylalanine dipeptide and peptide nanotubes (PNT), based on this process (FF PNT), are currently well studied, as they are of considerable interest due to their special structural and physical properties, which are important in various applications. However, single phenylalanine molecules can also form nanotubes and nanofibrils [64,65]. In [60], the modeling and assembly of a set of $(\mathrm{Phe})_{48}$ molecules into a helix-like tubular structure of a phenylalanine peptide nanotube (F48 PNT) using the molecular dynamics method (MD manipulator) was considered. Data on the formation of nanotubes of the "right" (D-F48 PNT) chirality from the initial L-F peptides and nanotubes of the "left" (L-F48 PNT) chirality from the D-F peptides were obtained.

In this work, using the approach described in [66], based on the values of the dipole moments of individual peptides, we calculated the sign and magnitude of chirality for such a phenylalanine spiral nanotube [60].

\subsection{Methods for Evaluating the Chirality of Regular Helical and Irregular Protein Secondary Structures}

According to M. Petitjean, the measure of chirality should be of a continuous characteristic and should be determined for a space of any dimension, and the chirality index should not depend on the method of selecting the mirror image [67]. At present, there are a significant number of works in which various methods for evaluating the chirality of helical structures are proposed. The main methods are as follows: a "connectivity index" for alkanes depending on physical parameters [68-70], binary code for benzenoids in 2D space [71], the deviation of a chiral set from a reference achiral set [72], chirality as overlapping the initial set with its mirror image [73], a measure of continuous symmetry based on determining the distance from a distorted molecular shape to a selected symmetry element [74,75], pseudoscalar measures of electronic chirality for molecular systems using the rotational polarizability of molecules [76], calculating the "degree of chirality" based on the overlap and an infinite hierarchy of pseudoscalar parameters for spiral ribbons, using a two-dimensional plane [77]. The described methods are often highly specialized and, as a rule, provide an estimate of symmetry, not chirality, and are fairly difficult to calculate, even if they are not based on experiments. The folding of peptide chains by rotating the planes of peptide bonds, relative to their bonds with $\alpha$-carbon atoms, is described by dihedral angles, the values of which provide the basis for assessing the chirality of proteins in the Ramachandran method, which allows for the observation of the predominant conformation of elements of the secondary structure of biomolecules [78]. Since its inception, this method has become the main method for characterizing proteins. In [79], the structural RP-analysis of proteins was extended from a two-dimensional map to a three-dimensional one, and a quantitative degree of chirality was added as a continuous measure of chirality (CCM), covering all bond angles and bond lengths of the amino acid residue at each point of the map. The addition of chirality to the Ramachandran plots made it possible to emphasize the sensitivity of the protein structure to minor conformational changes. It has been shown that points with higher values of chirality are special transition points in a protein, such as bends of the $\alpha$-helix, twisting of $\beta$-chains [80]. The authors of [81] presented a method 
based on the consideration of a peptide framework as a helix with axial (d) and angular $(\theta)$ displacements, which were obtained based on the co-ordinates of the peptide framework and dihedral angles. The method is used to characterize each region of the Ramachandran plot for both cis $\left(\omega=0^{\circ}\right)$ and trans $\left(\omega=180^{\circ}\right)$ peptides.

There are several main approaches used in recognizing and modeling turns and loops. In [82], the parameters of loops and turns that are similar in the length and geometry of their endpoints are used. The mechanisms for searching for structural motifs are described in [83]: the extension of the DeepView/Swiss-PdbViewer algorithms allows for the determination of structural motifs in a large databases of protein structures. The knob-socket model serves to determine the role of coils and turns within a tertiary structure. In the works of various authors for $\beta$-turns, the dihedral angles $\varphi, \psi$ are calculated on the Ramachandran plots [47,84-89]. Several statistical and computational methods for determining the structure of $\gamma$-turns are described. In particular, in [90], a method for recognizing $\gamma$-turns using neural networks was proposed. The determination of the structural characteristics of the loops seems to be especially difficult since their residues do not correspond to the pattern of dihedral angles or hydrogen bonds. The average prediction accuracy is primarily limited by the accuracy of the energy function, not by the degree of conformational sampling [91]. Attempts to determine rotations by including the interaction with the participation of atoms of the side chains in the analysis were made [92,93].

We considered the estimated chirality of the helices in [94,95]. In this paper, we describe in more detail the mathematical aspects of the solution. According to the mentioned method for the assessment of the chirality sign of helical structures, the mutual arrangement of $\alpha$-carbons-reference points in the helices provides a sufficient condition $[66,94,95]$. The chirality sign of secondary helical structures can be assessed by the sum of mixed products for triples of vectors $\left(\mathbf{v}_{i}\right)$ built between successive reference points $C \alpha$ as follows:

$$
\chi_{\text {total }}=\sum_{i=1}^{n-3}\left(\left[\mathbf{v}_{i}, \mathbf{v}_{i+1}\right], \mathbf{v}_{i+2}\right),
$$

where the original vectors are calculated by taking into account the $\mathrm{C} \alpha$ coordinates presented in the PDB (Figure 1)

$$
\left(\left[\mathbf{v}_{1}, \mathbf{v}_{2}\right], \mathbf{v}_{3}\right)=\left(y_{1} z_{2}-y_{2} z_{1}\right) x_{3}+\left(z_{1} x_{2}-z_{2} x_{1}\right) y_{3}+\left(x_{1} y_{2}-x_{2} y_{1}\right) z_{3} .
$$

In [94], we proposed a model for the normalized value of the chirality of protein helical structures as follows:

$$
\chi_{\text {norm }}=\sum_{i=1}^{n-3} \frac{\left(\left[\mathrm{v}_{i}, \mathrm{v}_{i+1}\right], \mathrm{v}_{i+2}\right)}{\mathrm{C}_{i}},
$$

where the normalization factor is calculated as $C_{i}=\left(\frac{1}{3} \sum_{j=0}^{2}\left|\mathrm{v}_{i+j}\right|\right)^{k}$.

The chirality normalization was calculated based on considering the chirality value of the helix as a physical object, which should tend to a certain value with an increase in the number of reference points (that is, with an increase in the density of points). Therefore, each mixed product is normalized to the power $k$ of the average length of the vectors.

To find the value of $k$, we establish the behavior of the chirality characteristic $\chi$ when the length of the vectors connecting the reference points changes. To execute this, consider a helix of radius $R$ and height $H$. Let there be $N$ reference points on this turn. We then performed all calculations in cylindrical coordinates. The origin of the coordinates coincides with the middle of the turn (Figure 2). 


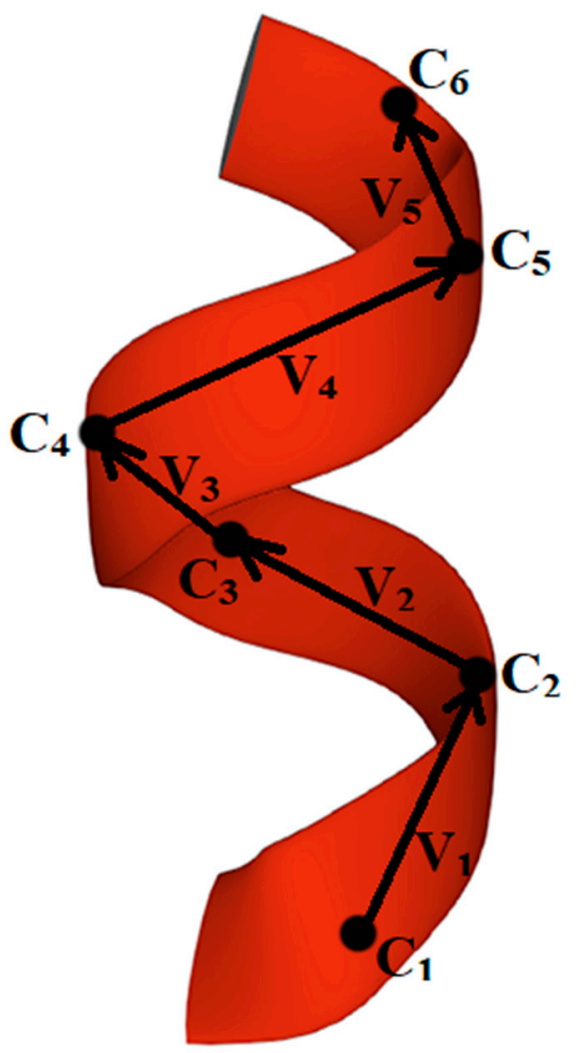

Figure 1. Graphic construction of vectors $\mathbf{v}_{i}$ for calculating the mixed vector product of helical protein structure (1L63 [96], $\alpha$-helix, residues 45-50). $\mathrm{C}_{i}$-atoms of $\alpha$-carbons, reference points in helix.

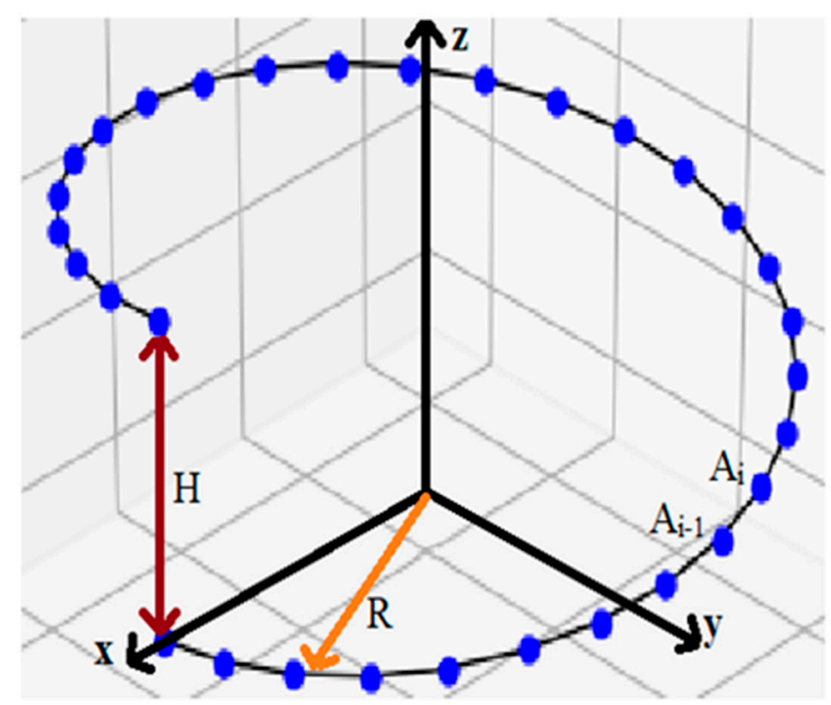

Figure 2. Normalization of chirality. The blue dots are reference points for this structure.

Then, the coordinates of the $i$-th point of the turn (denote it $A_{i}$ ):

$$
A_{i}:\left(R \cos \varphi_{i} ; R \sin \varphi_{i} ; i h\right), \text { where } i=0 \ldots N, h=\frac{H}{N}, \varphi_{i}=i \varphi\left(\varphi=\frac{2 \pi}{N}\right) .
$$


In accordance with this, the coordinates of the $\overrightarrow{r_{i}}$ vector connecting the points $A_{i-1}$ and $A_{i}$ have the following form:

$$
\overrightarrow{r_{i}}:\left\{R \cos \varphi_{i}-R \cos \varphi_{i-1} ; R \sin \varphi_{i}-R \sin \varphi_{i-1} ; h\right\} .
$$

Consider separately the $x$ and $y$ foordinates of the $\overrightarrow{r_{i}}$ vector:

$$
\begin{gathered}
\text { Consider separately the } x \text { and } y \text { foordinates of the } \overrightarrow{r_{i}} \text { vector: } \\
x_{i}=R\left(\cos \varphi_{i}-\cos \varphi_{i-1}\right)=-2 \sin \left[\frac{1}{2}\left(\varphi_{i}+\varphi_{i-1}\right)\right] \sin \left[\frac{1}{2}\left(\varphi_{i}-\varphi_{i-1}\right)\right]=-2 \sin [(2 i-1) \varphi] \sin \frac{\varphi}{2}, \\
y_{i}=R\left(\sin \varphi_{i}-\sin \varphi_{i-1}\right)=2 \sin \left[\frac{1}{2}\left(\varphi_{i}-\varphi_{i-1}\right)\right] \cos \left[\frac{1}{2}\left(\varphi_{i}+\varphi_{i-1}\right)\right]=2 \sin \varphi \cos [(2 i-1) \varphi] .
\end{gathered}
$$

Using the obtained values for the coordinates, we calculate the modulus (length) of the $\overrightarrow{r_{i}}$ vector:

$$
\begin{aligned}
\left|\overrightarrow{r_{i}}\right| & =\sqrt[2]{x_{i}{ }^{2}+y_{i}{ }^{2}+z_{i}^{2}}=\sqrt[2]{h^{2}+R^{2}\left(\cos \varphi_{i}-\cos \varphi_{i-1}\right)^{2}+R^{2}\left(\sin \varphi_{i}-\sin \varphi_{i-1}\right)^{2}} \\
& =\sqrt{h^{2}+4\left(\sin \frac{\varphi}{2}\right)^{2} R^{2}\left(\sin \left[\frac{(2 i-1) \varphi}{2}\right]^{2}+\cos \left[\frac{(2 i-1) \varphi}{2}\right]^{2}\right)}=\sqrt{h^{2}+4\left(\sin \frac{\varphi}{2}\right)^{2} R^{2}}
\end{aligned}
$$
formula:

The chirality characteristic, as already mentioned, is calculated using the following

$$
\chi=\sum_{i=1}^{N-3}\left(\left[\overrightarrow{r_{i}}, \overrightarrow{r_{i+1}}\right], \overrightarrow{r_{i+2}}\right) .
$$

Consider the vector product in (6) and take into account that the coordinates of the vectors are calculated by Formulas (3) and (4). Then

$$
\begin{aligned}
{\left[\overrightarrow{r_{i}}, r_{i+1}\right] } & =\left|\begin{array}{ccc}
i & j & k \\
x_{i} & y_{i} & z_{i} \\
x_{i+1} & y_{i+1} & z_{i+1}
\end{array}\right| \\
& =\vec{i} h R\left(2 \sin \frac{\varphi}{2} \cos \frac{2 i-1}{2} \varphi-2 \sin \frac{\varphi}{2} \cos \frac{2 i+1}{2} \varphi\right) \\
& +\vec{j} h R\left(2 \sin \frac{\varphi}{2} \sin \frac{2 i-1}{2} \varphi-2 \sin \frac{\varphi}{2} \sin \frac{2 i+1}{2} \varphi\right) \\
& +\vec{k} 4 R^{2}\left(\sin \frac{\varphi}{2} \sin \frac{2 i+1}{2} \varphi \sin \frac{\varphi}{2} \cos \frac{2 i-1}{2} \varphi-\sin \frac{\varphi}{2} \cos \frac{2 i+1}{2} \varphi \sin \frac{\varphi}{2} \sin \frac{2 i-1}{2} \varphi\right) .
\end{aligned}
$$

Substituting Formula (7) into Equation (6), we obtain:

$$
\begin{aligned}
\left(\left[\overrightarrow{r_{i}}, \overrightarrow{r_{i+1}}\right], \overrightarrow{r_{i+2}}\right) & =4 h R^{2}\left(\sin \frac{\varphi}{2}\right)^{2}\left[-\left(\cos \frac{2 i-1}{2} \varphi-\cos \frac{2 i+1}{2} \varphi\right) \sin \frac{2 i+3}{2} \varphi\right. \\
& +\left(\sin \frac{2 i-1}{2} \varphi-\sin \frac{2 i+1}{2} \varphi\right) \cos \frac{2 i+3}{2} \varphi+\left(\sin \frac{2 i+1}{2} \varphi \cos \frac{2 i-1}{2} \varphi\right. \\
& \left.\left.-\cos \frac{2 i+1}{2} \varphi \sin \frac{2 i-1}{2} \varphi\right)\right] .
\end{aligned}
$$

Let us consider separately several terms in (11), taking into account trigonometric transformations:

$$
\begin{gathered}
\cos \frac{2 i-1}{2} \varphi \sin \frac{2 i+3}{2} \varphi=\frac{1}{2}(\sin (2 i+1) \varphi+\sin 2 \varphi), \\
\cos \frac{2 i+1}{2} \varphi \sin \frac{2 i+3}{2} \varphi=\frac{1}{2}(\sin (2 i+1) \varphi+\sin 2 \varphi), \\
\sin \frac{2 i-1}{2} \varphi \cos \frac{2 i+3}{2} \varphi=\frac{1}{2}(\sin (2 i+1) \varphi-\sin 2 \varphi), \\
\sin \frac{2 i+1}{2} \varphi \cos \frac{2 i+3}{2} \varphi=\frac{1}{2}(\sin (2 i+2) \varphi-\sin \varphi), \\
\sin \frac{2 i+1}{2} \varphi \cos \frac{2 i-1}{2} \varphi=\frac{1}{2}(\sin 2 i \varphi+\sin \varphi)
\end{gathered}
$$




$$
\sin \frac{2 i-1}{2} \varphi \cos \frac{2 i+1}{2} \varphi=\frac{1}{2}(\sin 2 i \varphi-\sin \varphi) .
$$

By opening the brackets and substituting Formulas (12)-(17) into (11), we obtain an expression for the mixed product:

$$
\begin{aligned}
\left(\left[\overrightarrow{r_{i}}, \overrightarrow{r_{i+1}}\right], \overrightarrow{r_{i+2}}\right) & =2 h R^{2}\left(\sin \frac{\varphi}{2}\right)^{2}[\sin (2 i+2) \varphi+\sin \varphi-\sin (2 i-1) \varphi \\
& -\sin 2 \varphi+\sin (2 i+1) \varphi-\sin 2 \varphi-\sin (2 i+2) \varphi+\sin \varphi+\sin 2 i \varphi+\sin \varphi-\sin 2 i \varphi \\
& +\sin \varphi]=2 h R^{2}\left(\sin \frac{\varphi}{2}\right)^{2}[4 \sin \varphi-2 \sin 2 \varphi] .
\end{aligned}
$$

The final expression for characterizing chirality is obtained by a summation of all the mixed products:

$$
\chi=\sum_{i=1}^{N-3}\left(\left[\overrightarrow{r_{i}}, \overrightarrow{r_{i+1}}\right], \overrightarrow{r_{i+2}}\right)=16(N-3) H R^{2}\left(\sin \frac{\varphi}{2}\right)^{4} \sin \varphi .
$$

Consider the behavior of $\chi(19)$ and $|\vec{r}|$ (8) as the number of reference points tends to infinity:

$$
\begin{gathered}
\lim _{N \rightarrow \infty} \chi=\lim _{N \rightarrow \infty} 16(N-3) H R^{2}\left(\sin \frac{\pi}{N}\right)^{4} \sin \frac{2 \pi}{N}=\lim _{N \rightarrow \infty} \frac{32(N-3) H R^{2} \pi^{5}}{N^{5}} \sim \frac{1}{N^{5}}, \\
\lim _{N \rightarrow \infty}|\vec{r}|=\lim _{N \rightarrow \infty} \sqrt{\frac{H^{2}}{N^{2}}+4\left(\sin \frac{\pi}{N}\right)^{2} R^{2}}=\lim _{N \rightarrow \infty} \frac{1}{N} \sqrt{H^{2}+4 \pi^{2} R^{2}} \sim \frac{1}{N} .
\end{gathered}
$$

Thus, as $N \rightarrow \infty \chi \sim|\vec{r}|^{5}$, therefore,

$$
\chi_{\text {norm }}=\frac{\chi}{|\vec{r}|^{5}} .
$$

Thus, to preserve the finite nonzero chirality with an unlimited increase in the number of points, one should take $k=5$.

The assessment of the chirality of irregular protein secondary structures is similar to that of regular structures. In this article, the chirality of irregular protein secondary structures was assessed using the example of $\beta-, \alpha$-turns and $\Omega$-loops (Figures $3-5$ ). A sufficient condition is provided by the relative position of the $\alpha$-carbon reference points in turns and loops. 


$$
\frac{\mathrm{CS}}{\mathrm{SH}}
$$




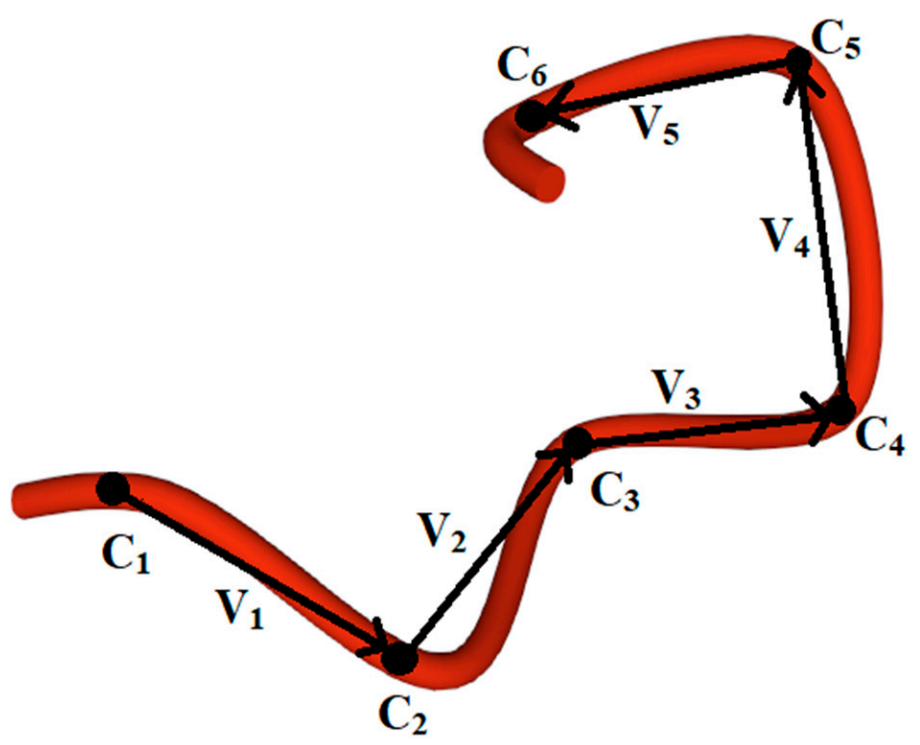

Figure 5. Graphic construction of $\mathbf{v}_{i}$ vectors for calculating the mixed vector product, $\Omega$-loop of the 2ACT protein [100] (residues 8-13). $C_{i}$-atoms of $\alpha$-carbons, reference points in the $\Omega$-loop.

The results of calculating the chirality of regular (helical) and irregular (turns and loops) protein secondary structures are presented in the Results section.

2.3. Method for Calculating the Chirality of Phenylalanine (F) Helical Peptide Nanotubes (PNT) from Successive Dipole Moments of Their Constituent Phenylalanine Molecules

Recently, in [60], a new approach was proposed for modeling various molecular nanostructures, determining the implementation of the molecular dynamics simulation (MDS) run trajectory, and forming the final structure using the so-called molecular dynamics manipulator (MDM). This approach is a type of MDS, developed based on the PUMA-CUDA software package [101,102], using the physics of the PUMA software package $[103,104]$. Using this tool allows for the exploration of the formation process of helical structures from a linear sequence of any amino acids. It was used in [60] to assemble nanotubes from linear phenylalanine chains of different chirality (L-F and D-F) by including additional force effects in the molecular dynamics simulation program for these structures.

In this work, using the obtained helical structures of phenylalanine nanotubes of different chirality [60], we calculate the magnitude and sign of their chirality using a method similar to that developed in [94,95] and applied in [66] to diphenylalanine helical structures, based on the procedure of the mixed product of three consecutive vectors in a coil of a spiral structure. To achieve this, we select one coil of the helix from each nanotube of different chirality and apply this calculation method to them based on the mixed product of vectors of dipole moments from a number of successive phenylalanine molecules that form this coil of the helix of a phenylalanine peptide nanotube (PNT), taking into account its chirality.

Helical-like PNT structures, based on phenylalanine of different chirality ( $\mathrm{L}$ and D), were obtained as a result of MD simulation (MDS) and their assembly [60], and consist of $48 \mathrm{~F}$ molecules and 4 coils in such structures of nanotubes of each chirality L-F48 and D-F48 (with coordinates of all atoms in standard *.pdb format) (Figure 6, Video S1). 

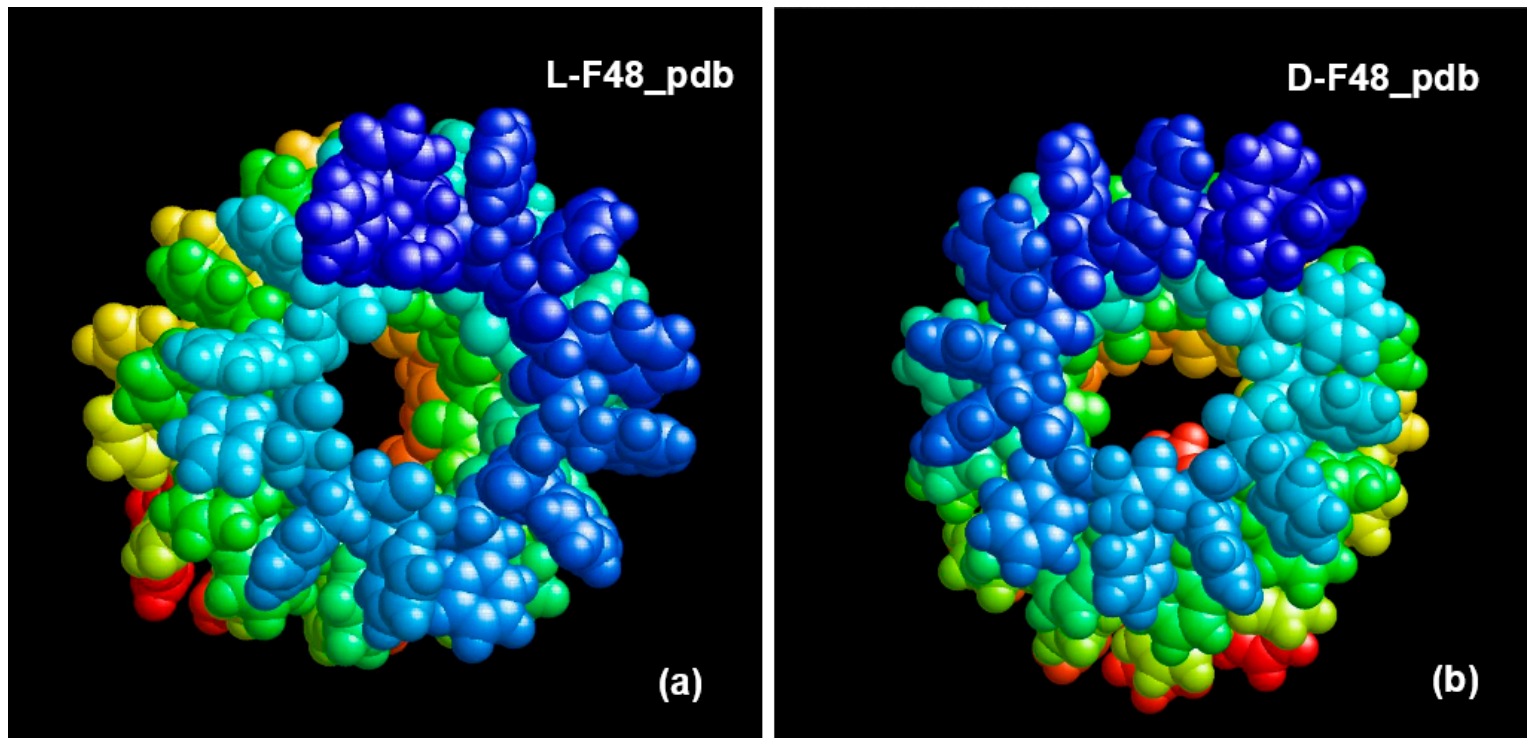

Figure 6. The obtained results of MDS and self-assembly of phenylalanine helical-like nanostructures: (a) L-F48_pdb; (b) D-F48_pdb (images were obtained from *.pdb files using the RasMol program http://www.openrasmol.org/ (accessed on 30 September 2021)).

We transferred dipole moments to the HyperChem [105] workspace (in *.hin format with Cartesian x, y, z coordinates for all atoms) for analysis (Figure 7).
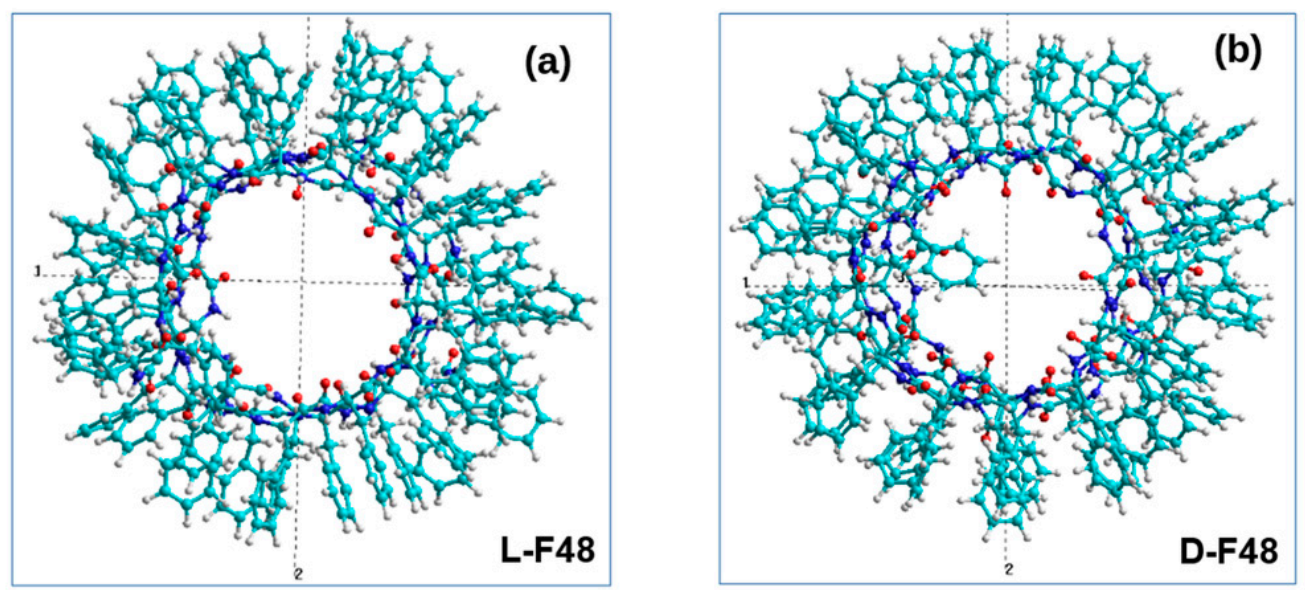

Figure 7. The obtained results of MDS and self-assembly of phenylalanine helical-like PNT nanostructures, transferred to HyperChem workspace (in Z-projection): (a) F48L PNT; (b) F48D-PNT.

We selected an individual coil at sequentially from each PNT helix consisting of four coils. When calculating the dipole moments of these coils we found that they have opposite directions to the vectors of the total dipole moments $\mathbf{D}_{\mathrm{L}-\mathrm{F}}$ for each $\mathrm{L}-\mathrm{F}$ and $\mathbf{D}_{\mathrm{D}-\mathrm{F}}$ for each D-F coils (Figure 8b,d). 

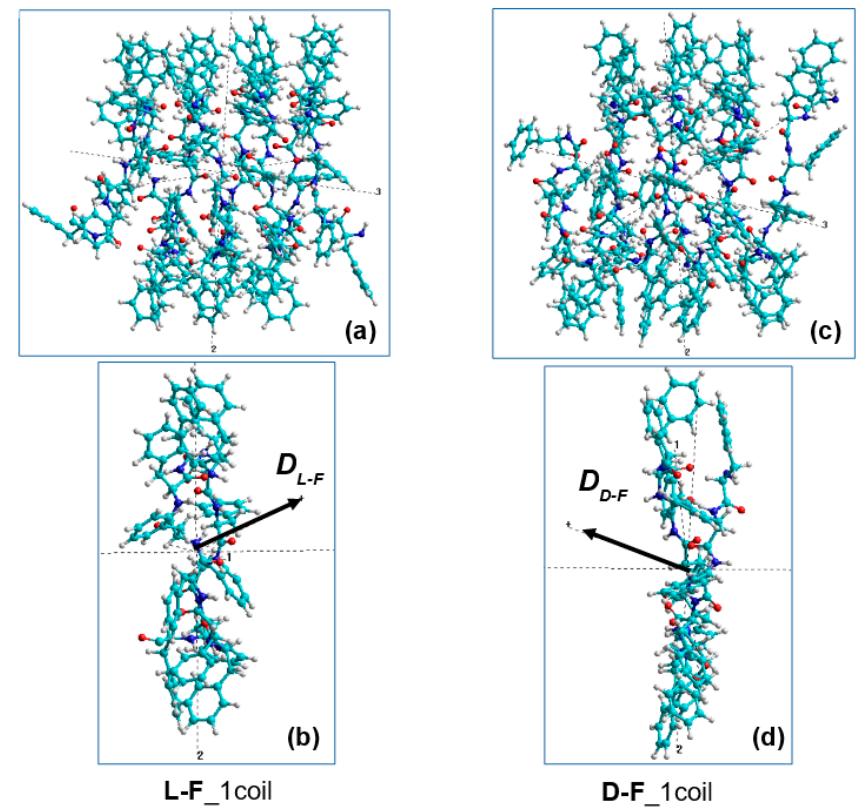

Figure 8. Selection of the one coil from the four in PNT helix-like structures (in X-projection): (a, b)-for the L-F PNT; (c, d)-for the D-F PNT.

We then selected each consequential phenylalanine $\mathrm{F}$ molecule from corresponding coil, containing $12 \mathrm{~F}$ molecules, and calculated its dipole moment $\mathbf{D}_{i}$ using various methods (from HyperChem package [105,106]), including the following: (1) quantum-chemical semiempirical RM1 RHF [106]; (2) classical molecular mechanical Amber method [105]. This procedure schematically shown in Figure 9.

Similarly to the calculation of diphenylalanine nanotubes [66], we use a similar successive set of $\mathrm{F}$ molecules for phenylalanine nanotubes. The origin of $\mathbf{D}_{i}$ vectors is obtained relative to the center of mass of the corresponding molecules. The absolute value of each dipole moment $\mathbf{D}_{i}$ is

$$
\mathbf{D}_{i}=\left|\mathbf{D}_{i}\right|=\sqrt{D_{x, i}^{2}+D_{y, i}^{2}+D_{z, i^{\prime}}^{2}}
$$

where $D_{x, i}, D_{y, i}$ and $D_{z, i}$ are the components of the $i$-th vector $\mathbf{D}_{i}$ in the Cartesian coordinates. Similar to Equation (1) [94,95], the sum of the scalar triple products of the dipole moments related to the PNT's chirality can be written as:

$$
c_{\text {total }}=\sum_{i=1}^{n-2}\left(\left[\mathbf{D}_{i}, \mathbf{D}_{i+1}\right], \mathbf{D}_{i+2}\right),
$$

It is necessary to note that the summation here has taken over $i$ in the range from 1 to $\mathrm{n}-2$, whereas in Equation (1), the $i$ range is from 1 to $\mathrm{n}-3$. Now $n=12$. This is because in supramolecular helixes $i$ numerates the individual molecules instead of the $\mathrm{C} \alpha$ atoms in proteins. The $c_{\text {total }}$ can be normalized over the average value of the total dipole momentum of the PNT's coil, $D_{a v}=\frac{1}{12} \sum_{i=1}^{12} D_{i}$, to obtain a universal measure of the chirality:

$$
c_{\text {norm }}=\frac{c_{\text {total }}}{D_{a v}^{3}} .
$$



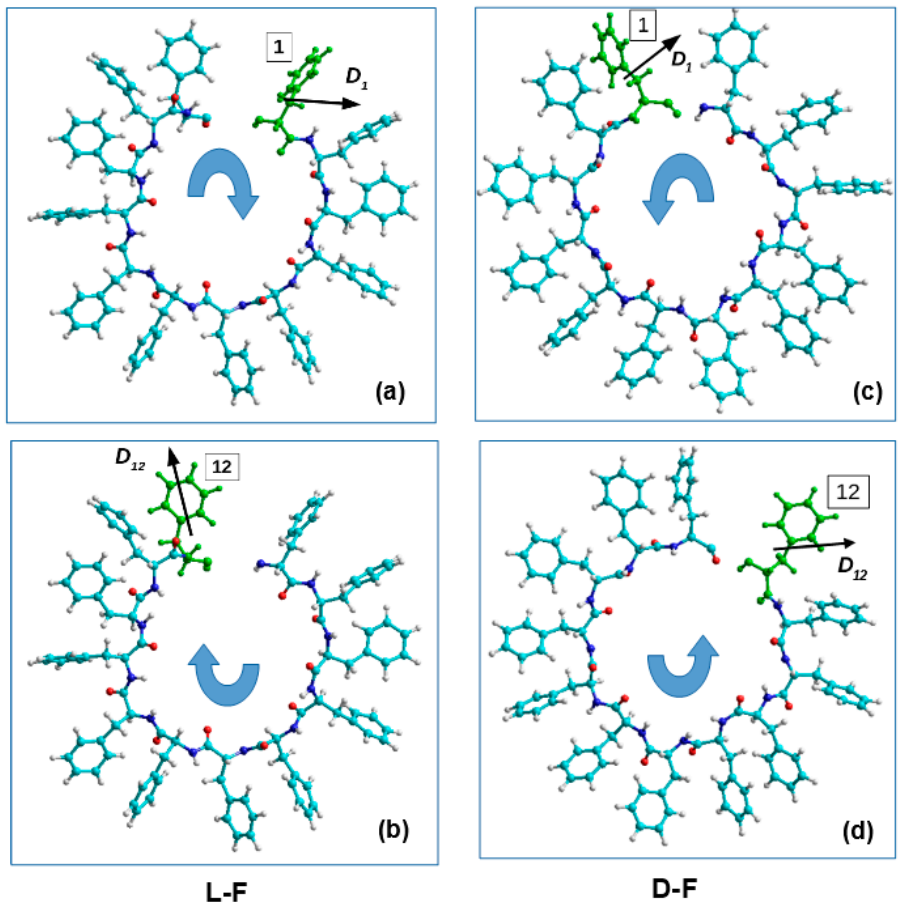

Figure 9. Schematic of the selection procedure of each consequential phenylalanine F molecule (from 1 up 12) from one corresponding coil of helix and the calculation of its dipole moment $\mathbf{D}_{i}$ (for $\mathrm{i}=1$, ... , 12) (in Z-projections): (a,b)-for the L-F PNT; (c,d)-for the D-F PNT, correspondingly.

Individual dipole moments of F molecules in one coil of helical PNTs were calculated using the semi-empirical quantum-mechanical method PM3 in the restricted Hartree-Fock approximation (RHF) and molecular force field method Amber from the HyperChem package $[105,106]$. The results for L-F and D-F are shown below in the Results section. A schematic representation of the spatial arrangement of $\mathrm{F}$ of the individual dipole moments $\mathbf{D}_{\boldsymbol{i}}$ in two PNT coils is presented in Figure 9a-d for L-F and for D-F PNT. The obtained results of calculating the magnitude and sign of chirality by Formulas (23)-(25) for each case ( $\mathrm{L}$ and $\mathrm{D})$ are presented in the Results section.

\section{Results}

\subsection{Helical Protein Secondary Structures}

Using the developed method, files from PDB with the data of 983 proteins of various classes were considered. The chirality of helical structures was calculated, and data for $\alpha-$ and 310 -helices (oxidoreductase, transferase, hydrolase, lyase, isomerase, ligase, translocase, chaperones, viruses, structural proteins, endo- and exocytosis proteins, electron transportprotein data of chirality) are presented in [95], as well as for $\pi$-helices (all $\pi$-helices are taken from [44]). In accordance with Formula (3), a map of normalized chirality for the considered helical protein structures is presented (Figure 10). 


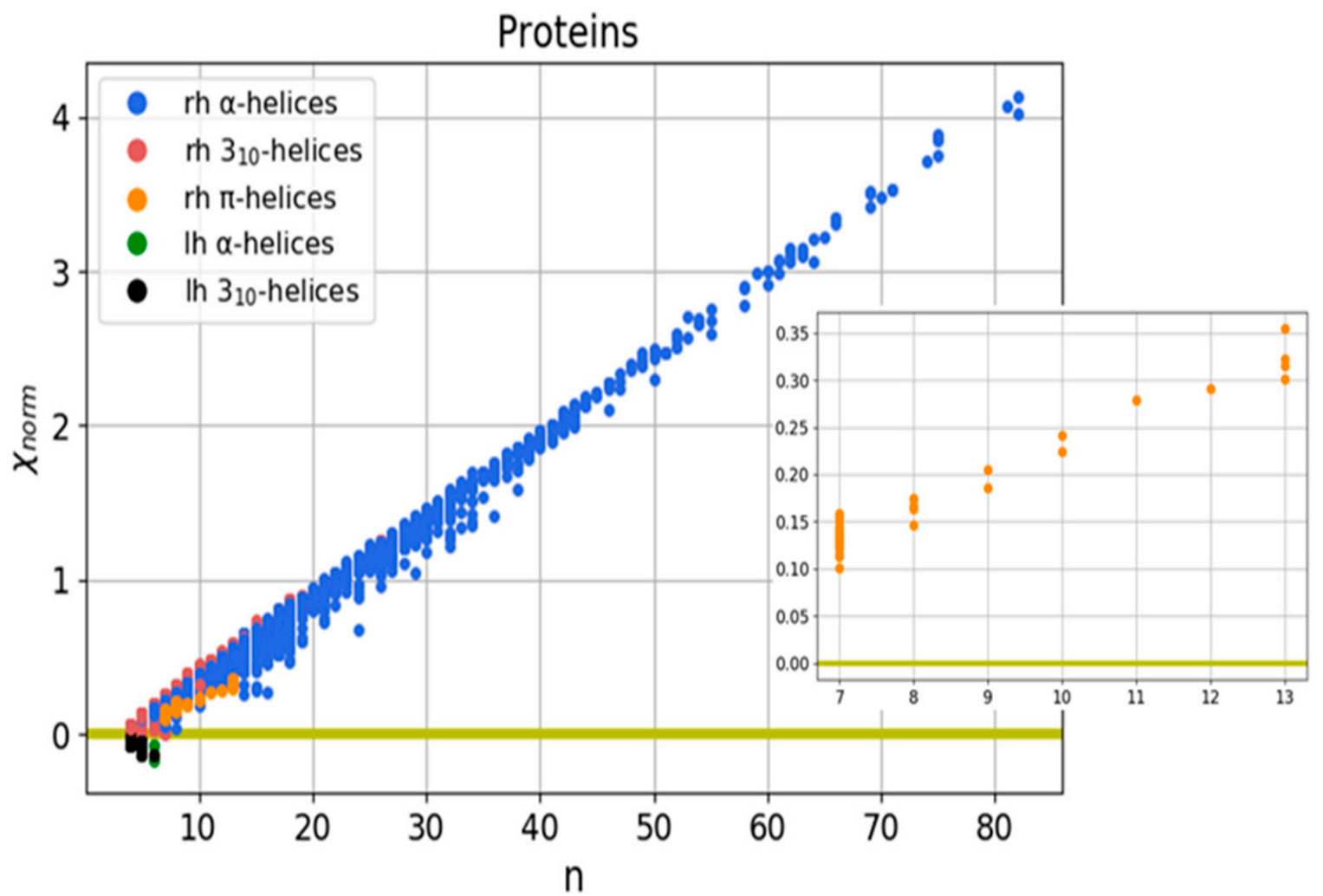

Figure 10. Normalized chirality map of protein helical structures. The horizontal axis is the length of the secondary structure in amino acid residues, the vertical axis is the normalized chirality value. The inset shows a map of $\pi$-helices; rh-right-handed structures, lh-left-handed structures.

The results obtained showed that for all the considered regular protein structures (helices), the developed measure of chirality $\left(\chi_{\text {norm }}\right)$ linearly depends on the number of atoms in the helix. Secondly, the results obtained are consistent with the literature data on the predominant conformation of right-handed helical structures.

The calculated data for $\alpha$ and $3_{10}$-helices were presented previously in our work [95]. The calculated parameters of $\pi$-helices are presented in Table A1.

\subsection{Irregular Protein Secondary Structures}

We estimated the chirality of $\alpha$-turns (Figure 3) on the basis of the data presented in [98], where all $\alpha$-turns are classified depending on the value of the torsion angles $(\varphi, \psi)$ for various amino acid residues that comprise the turns. Based on this, the authors distinguish 9 types of $\alpha$-turns, including two types of F1 and F2, called families, as well as seven less common types g1, g2, g3, g4, g5, g6, g7, termed groups. In addition, the two turns identified were not included in any of the groups. We examined $78 \alpha$-turns identified by the authors of [98], calculated the chirality for each turn using our described method, and obtained the mean values and standard deviations of chirality for each type. It follows that most of these types have certain chirality values characteristic of each type of $\alpha$-turn. The calculation results are presented in Table 1. The classes for $\alpha$-turns are presented in Table A2. 
Table 1. Mean values of chirality and standard deviations for $\alpha$-turns of various types [98], calculated using the method for evaluating the chirality of regular helical and irregular protein secondary structures.

\begin{tabular}{cccc}
\hline Type of $\alpha$-Turn & Number & $\begin{array}{c}\text { Mean Chirality } \\
\text { Value }\end{array}$ & Standard Deviation \\
\hline F1 & 46 & 0.08628 & 0.01473 \\
F2 & 8 & 0.06922 & 0.013 \\
g1 & 5 & -0.03274 & 0.00846 \\
g2 & 2 & -0.04165 & 0.00864 \\
g3 & 4 & 0.02838 & 0.02813 \\
g4 & 4 & -0.06686 & 0.00568 \\
g5 & 3 & 0.10221 & 0.00191 \\
g6 & 3 & -0.00376 & 0.00415 \\
g7 & 2 & 0.09378 & 0.02175 \\
Other & 2 & 0.0323 & 0.05972 \\
\hline
\end{tabular}

For $\beta$-turns (Figure 4 ), we performed similar calculations using the database presented in [89]. Article [89] presents a new classification of $\beta$-turns based on an algorithm for their identification and recognition, implemented in the form of a computer program. The authors divided all $\beta$-turns into 18 types, in addition to those that were not included in any of the newly formed groups, based on the following criteria: the distance between the first and last residues of turn, the values of torsion angles $(\varphi, \psi)$ for the second and third amino acid residues, and the conformation of these residues relative to peptide bonds (cis/trans). Using the computer program of the authors of [89], we distinguished 850 uniquely determined $\beta$-turns from 20 proteins taken from the PDB [107] and calculated the mean values and standard deviations of chirality for each type (Table 2).

Table 2. Mean values and standard deviations of chirality for $\beta$-turns of various types (according to [89]), calculated using the method for evaluating the chirality of regular helical and irregular protein secondary structures. The proteins with $\beta$-turns are hydrolases.

\begin{tabular}{cccc}
\hline Type of $\beta$-Turn & Number & Mean Chirality Value & Standard Deviation \\
\hline AD & 481 & 0.05041 & 0.01634 \\
Pd & 61 & 0.02132 & 0.01371 \\
Pa & 36 & 0.00392 & 0.02101 \\
ad & 60 & -0.05916 & 0.00556 \\
AB1 & 17 & 0.00647 & 0.01820 \\
AZ & 16 & 0.04043 & 0.01255 \\
AB2 & 3 & 0.04561 & 0.00151 \\
pD & 30 & -0.01805 & 0.02312 \\
AG & 6 & 0.06884 & 0.00086 \\
BcisP & 10 & 0.03700 & 0.01090 \\
dD & 5 & 0.05961 & 0.01223 \\
PcisD & 10 & 0.00591 & 0.01596 \\
dN & 6 & 0.05235 & 0.00206 \\
Dd & 5 & -0.06710 & 0.00107 \\
cisDA & 6 & 0.06506 & 0.00022 \\
pG & 7 & 0.00086 & 0.02898 \\
cisDP & 3 & 0.04490 & 0.02358 \\
other & 88 & 0.02855 & 0.03472 \\
\hline
\end{tabular}

The calculation results showed that, for most types of $\beta$-turns, there are certain ranges of chirality values, which also confirms the correctness of such a classification of these structures $\mathbf{s}$ found in [89]. Based on the calculations performed (Tables 1, 2 and A2), a chirality map was obtained for the considered $\alpha$ - and $\beta$-turns (Figure 11). 


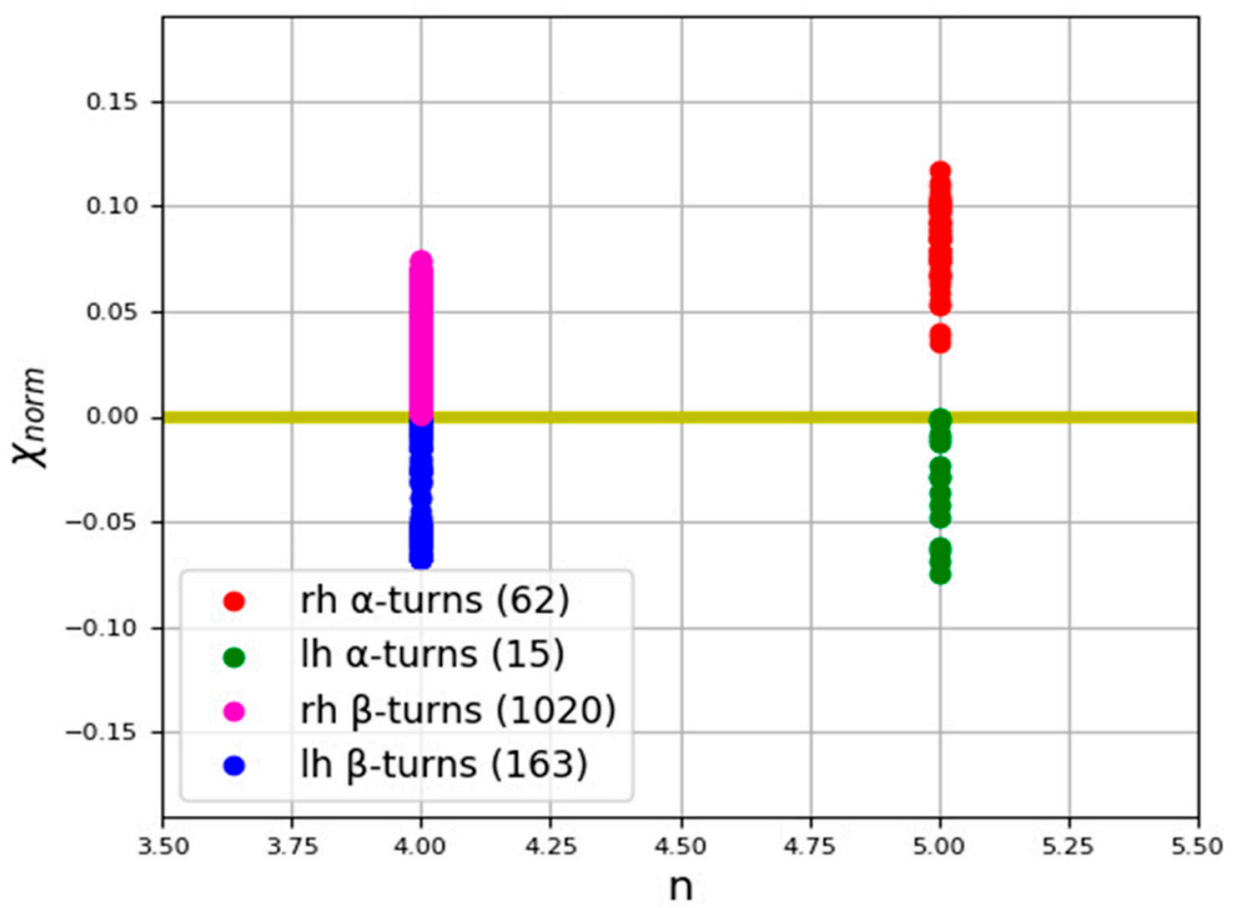

Figure 11. Normalized chirality map of $\alpha$ - and $\beta$-turns (mean values of various types presented in Tables 1 and 2). The horizontal axis is the length of the secondary structure in amino acid residues, the vertical axis is the normalized chirality value; rh-right-handed structures, lh-left-handed structures.

An analysis of the normalized chirality map of $\alpha$ - and $\beta$-turns (Figure 11) indicates that, for all the considered proteins, the measure of chirality $\left(\chi_{\text {norm }}\right)$ of turns linearly depends on the number of atoms in these structures (see data in Tables 1 and 2). However, since all considered $\beta$-turns consist of 4 amino acid residues, and $\alpha$-turns consist of 5 residues, they are located parallel to the $\mathrm{Y}$-axis on the map.

To calculate the chirality of the $\Omega$-loops (Figure 5), the data in [57] were utilized. The chirality calculation data for $190 \Omega$-loops are presented on the chirality map (Figure 12) and in Table A3.

The spatial orientation of the loops clearly affects the quantitative values of the chirality of these structures. Let us consider a stepwise change in chirality in the process of calculating the total chirality of the loop structure using the example of a loop from the 2ACT protein (Figure 5). Depending on the number of consecutive residues used for calculation, the chirality can be altered either upwards or downwards (Table 3).

Table 3. Stages of calculating the chirality value of the $\Omega$-loop, 2ACT protein (residues 8-13) [100].

\begin{tabular}{ccccc}
\hline Number of Residues & Number of Vectors & $\begin{array}{c}\text { Number of Mixed } \\
\text { Products }\end{array}$ & $\begin{array}{c}\text { Addition to the Chirality } \\
\text { Value at This Step }\end{array}$ & $\begin{array}{c}\text { Total Chirality Value at } \\
\text { This Step }\end{array}$ \\
\hline 1 & - & - & 0 & 0 \\
2 & 1 & - & 0 & 0 \\
3 & 2 & - & 0 & 0 \\
4 & 3 & 1 & -0.0534 & 0.0554 \\
5 & 4 & 2 & 0.0585 & -0.0077 \\
6 & 5 & 3 & & 0.0508 \\
\hline
\end{tabular}




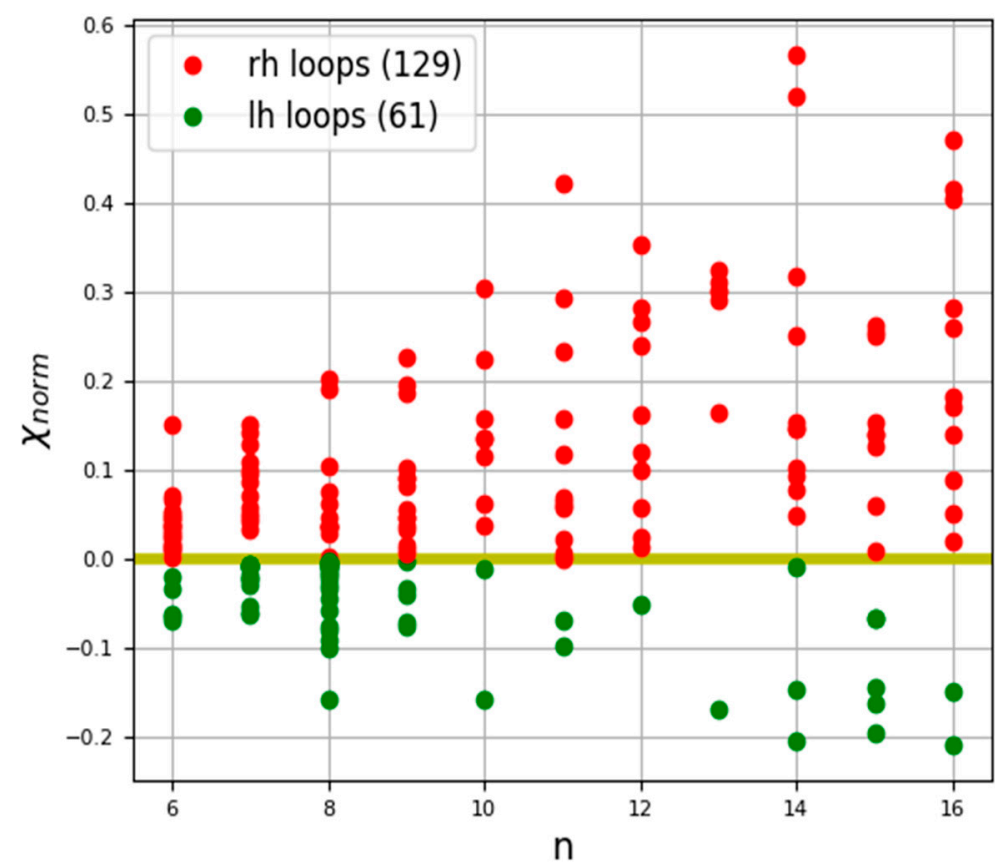

Figure 12. Normalized chirality map of $\Omega$-loops. The horizontal axis is the length of the secondary structure in amino acid residues, the vertical axis is the normalized chirality value; rh-right-handed structures, lh-left-handed structures.

\subsection{Phenylalanine (F) Helix-like Peptide Nanotubes}

Following the method for calculating the chirality of phenylalanine (F) helix-like peptide nanotubes (PNT), the results of calculating the dipole moments for the sequence of individual amino acids of phenylalanine $\mathrm{F}$ from the turns of spiral nanotubes of different chirality are presented. Nanotubes were obtained by coiling a linear sequence of amino acid F, initially with a different chirality of L-F and D-F (by the molecular dynamics method according to [60]). The obtained results of calculating the magnitude and sign of chirality by Formulas (23)-(25) for each case ( $\mathrm{L}$ and $\mathrm{D}$ ) are presented in Tables 4-6.

Table 4. Values of dipole moments for a coil of the helix-like L-F PNT computed using RM1 (RHF) and Amber (after RM1) methods. All values of dipole moments are given in Debye units.

\begin{tabular}{|c|c|c|c|c|c|c|c|c|}
\hline \multirow{2}{*}{$i$} & \multicolumn{4}{|c|}{ RM1 RHF } & \multicolumn{4}{|c|}{ Amber } \\
\hline & $D i$ & $D x$ & $D y$ & $D z$ & $D i$ & $D x$ & $D y$ & $D z$ \\
\hline 1 & 2.730 & 2.625 & -0.697 & 0.282 & 2.915 & 2.740 & -0.955 & -0.282 \\
\hline 2 & 3.400 & 2.884 & 0.360 & -1.765 & 2.937 & 2.232 & 1.075 & -1.578 \\
\hline 3 & 2.488 & 1.645 & 1.503 & 1.106 & 2.624 & 0.984 & 1.348 & 2.025 \\
\hline 4 & 2.615 & 1.710 & 1.869 & 0.650 & 2.671 & 2.086 & 1.603 & 0.463 \\
\hline 5 & 2.558 & -0.760 & 2.203 & 1.054 & 2.844 & -1.325 & 1.618 & 1.928 \\
\hline 6 & 2.449 & -0.956 & 2.224 & 0.370 & 2.564 & -0.554 & 2.429 & -0.608 \\
\hline 7 & 2.997 & -1.096 & 0.851 & -2.656 & 2.372 & -1.185 & -0.194 & -2.046 \\
\hline 8 & 2.258 & -1.456 & 0.790 & -1.534 & 1.631 & -0.631 & 0.534 & -1.406 \\
\hline 9 & 2.436 & -1.265 & -1.928 & -0.785 & 2.691 & -2.137 & -1.636 & -0.026 \\
\hline 10 & 2.611 & -1.789 & -1.795 & 0.630 & 1.504 & -1.081 & -0.999 & 0.310 \\
\hline 11 & 1.887 & -0.942 & -0.771 & -1.442 & 1.165 & -1.135 & -0.254 & 0.068 \\
\hline 12 & 2.201 & -0.996 & -1.873 & 0.586 & 1.771 & -0.819 & -1.533 & -0.338 \\
\hline Dsum & 30.630 & -0.396 & 3.433 & -3.504 & 27.692 & 2.111 & 3.036 & -2.138 \\
\hline Dcoil & 9.995 & 6.624 & 2.820 & -6.934 & 6.3004 & 4.2597 & 2.0522 & -4.164 \\
\hline Dav & 2.553 & & & & 2.308 & & & \\
\hline
\end{tabular}


Table 5. Values of dipole moments for a coil of the helix-like D-F PNT computed using RM1 (RHF) and Amber (after RM1) methods. All values of dipole moments are given in Debye units.

\begin{tabular}{|c|c|c|c|c|c|c|c|c|}
\hline \multirow{2}{*}{$i$} & \multicolumn{4}{|c|}{ RM1 RHF } & \multicolumn{4}{|c|}{ Amber } \\
\hline & $D i$ & $D x$ & $D y$ & $D z$ & $D i$ & $D x$ & $D y$ & $D z$ \\
\hline 1 & 2.992 & -2.037 & 2.152 & 0.414 & 3.041 & -2.109 & 1.870 & 1.142 \\
\hline 2 & 3.676 & -3.516 & -0.872 & -0.630 & 2.980 & -2.724 & -0.862 & -0.846 \\
\hline 3 & 2.864 & -2.084 & -1.822 & -0.735 & 2.727 & -1.612 & -1.660 & -1.443 \\
\hline 4 & 2.943 & 0.259 & -2.654 & 1.244 & 2.797 & -0.790 & -2.055 & 1.726 \\
\hline 5 & 2.746 & 0.852 & -2.590 & -0.325 & 2.780 & 1.098 & -2.542 & 0.245 \\
\hline 6 & 2.821 & 1.415 & -2.392 & -0.483 & 3.192 & 1.285 & -2.357 & -1.726 \\
\hline 7 & 3.781 & 1.444 & -3.251 & 1.282 & 3.691 & 1.197 & -2.894 & 1.953 \\
\hline 8 & 2.503 & 1.317 & 2.048 & 0.578 & 2.387 & 2.070 & 1.060 & -0.539 \\
\hline 9 & 2.888 & 1.720 & 1.513 & 1.758 & 2.483 & 1.376 & 1.563 & 1.353 \\
\hline 10 & 3.282 & -1.128 & 2.525 & 1.766 & 2.732 & -0.748 & 2.323 & 1.230 \\
\hline 11 & 3.762 & -3.239 & 1.798 & 0.657 & 3.072 & -2.448 & 1.774 & 0.547 \\
\hline 12 & 2.667 & -2.229 & 0.793 & -1.231 & 2.836 & -2.774 & 0.589 & 0.034 \\
\hline Dsum & 36.925 & -7.224 & -2.752 & 4.294 & 34.718 & -6.179 & -3.191 & 3.675 \\
\hline Dcoil & 9.599 & -6.395 & -5.676 & 4.362 & 8.234 & -4.333 & -5.081 & 4.818 \\
\hline$D a v$ & 3.077 & & & & 2.893 & & & \\
\hline
\end{tabular}

RM1: $(\text { Dav })^{3}=29.134$ Debye $^{3}$; Amber: $(\text { Dav })^{3}=24.217$ Debye $^{3}$.

Table 6. Magnitudes and signs of the chirality obtained for L-F and D-F PNTs for various calculating methods.

\begin{tabular}{ccccc}
\hline Type of PNT & \multicolumn{2}{c}{ L-F } & & D-F \\
\hline Calculating method & RM1 RHF & Amber & RM1 RHF & Amber \\
$c_{\text {total }}$, Debye & 20.266 & 18.171 & -19.647 & -26.204 \\
$c_{\text {norm }}$ & 1.219 & 1.479 & -0.674 & -1.082 \\
Chirality sign & positive & positive & negative & negative \\
\hline Chirality symbol & D & D & L & L
\end{tabular}

Table 6 shows the magnitude and sign of chirality, calculated using the formulas for the mixed product of dipole moments (23)-(25).

The obtained results (Table 6) reveal a characteristic change in the sign of chirality during transition to a higher level of organization, which is observed in the structures of biomacromolecules [8,9]. The calculated chirality of a spiral nanotube, based on the L-F initial amino acid, was found to have a positive sign-D type, and the chirality of the D-F-based nanotube has a negative sign corresponding to the L chirality type.

Note that the data presented here for the cube of average values for the absolute value of the total dipole moment $D_{a v}=\frac{1}{12} \sum_{i=1}^{12} D_{i}$ of each of the $\mathrm{F}$ amino acids, represent the average volume built on three consecutive vectors of the mixed product of these vectors. For each group of three such vectors, the calculated value of the magnitude of their mixed product changes, corresponding to the volume on these three vectors. hereby normalizing for the average value $\left(D_{a v}\right)^{3}$ according to Formula (25), we obtain the relative change in volume, with a slight change around " 1 ". Moreover, for the left-handed and right-handed triplets of vectors, the corresponding volumes have different signs, which leads to a change in sign in this case.

\section{Discussion}

A chirality analysis was conducted for 26,150 helical structures, namely, 21,702 $\alpha$ helices, 4360310 -helices, and $88 \pi$-helices (all studied $\pi$-helices were taken from [44]). Research has shown that most of the helical structures are right-handed. Among the structures studied, we found 21,689 right-handed $\alpha$-helices, 4160 right-handed $3{ }_{10}$-helices, 
and 88 right-handed $\pi$-helices. To study the chirality of $\pi$-helices, 84 proteins were analyzed, including 23 oxidoreductases, 22 hydrolases, 8 lyases, 7 transferases, 5 isomerases, 4 binding proteins, 2 toxins, 2 photosynthetic proteins, 2 signal proteins, 1 electron transport protein, 1 luminescent protein, 1 viral protein, 1 protein of endo- and exocytosis, 1 oxygen transport protein, 1 ion transport protein, 1 antibiotic, 1 adhesion protein and 1 iron transport protein (Table A1).

The obtained results show that, for regular helical protein secondary structures (the data for the chirality of $\alpha$ - and $310^{-}$-helices are presented in [95]), the data for $\pi$-helices are in Table A1), the developed measure of chirality $\left(\chi_{\text {norm }}\right)$ linearly depends on the number of atoms in the helix (Figure 10). For irregular protein secondary structures ( $\beta$-turns-Table 2 , $\alpha$-turns-Table A2, $\Omega$-loops-Table A3), a different picture emerges. Since all of the considered $\beta$-turns consist of 4 amino acid residues, and $\alpha$-turns consist of 5 residues, they were found to be located parallel to the Y-axis on the chirality map (Figure 11). The spatial orientation of $\Omega$-loops, in contrast to turns, consists of different numbers of amino acid residues, but unlike regular helices, they are characterized by different spatial orientations. These features affect the quantitative values of the chirality of the loops, whereby, depending on the number of consecutive residues taken for the calculation, the chirality can be altered either upwards to or downwards (Figure 12, Table 3).

Irregular protein secondary structures connect regular protein secondary structures and play a key role in the formation of a protein globule [56]. Given the frequency of occurrence of $\alpha$-, $\beta$-turns, and $\Omega$-loops, this study acts as a useful tool for studying the structure of proteins, both natural and artificial, as well as for protein design and materials science.

The results obtained for calculating the magnitude and sign of chirality, for L- and D-nanotubes based on phenylalanine (Tables 4-6), are similar to the data of other works on modeling peptide and dipeptide nanotubes of different chirality and experimental data [61-63,108]. These data also fully comply with the regularity of the change in the chirality sign of molecular structures with the complication of their hierarchical level of organization $[8,9]$. Therefore, this method for calculating the magnitude and sign of chirality by the mixed product method of Sidorova et al. [94,95], using the values of dipole moments in the sequence of individual peptides and dipeptides (or amino acids) as vectors, is found to be suitable, and can be successfully applied for assessments on the magnitude and sign of chirality of complex self-organizing helix-like nanostructures based on amino acids, as well as peptides and dipeptides.

Supplementary Materials: The following are available online at https:/ / www.mdpi.com/article/10 $.3390 /$ nano11123299/s1, Video S1: Assembly of a left-handed nanotube based on 48 phenylalanine D-monomers.

Author Contributions: Conceptualization, A.S. and V.B.; methodology, A.S., A.L., D.S., I.L. and V.B.; software, A.L., D.S. and I.L.; validation, A.L., D.S. and I.L.; formal analysis, A.S., V.B. and E.B.; writing-original draft preparation, A.S. and V.B.; writing—review and editing, A.S. and E.B.; visualization, A.L., D.S., I.L. and V.B.; supervision, A.S. and V.B. All authors have read and agreed to the published version of the manuscript.

Funding: This research was funded by the Russian Foundation for Basic Research, grant n. 20-5153014_GFEN_a.

Institutional Review Board Statement: Not applicable.

Informed Consent Statement: Not applicable.

Data Availability Statement: The data presented in this study are available on request from the corresponding author.

Acknowledgments: The authors are grateful to the Russian Foundation for Basic Research, grant $\mathrm{n}$. 19-01-00519-a. The authors are grateful to V.A. Tverdislov for useful discussions.

Conflicts of Interest: The authors declare no conflict of interest. 


\section{Appendix A}

Table A1. The calculated parameters of $\pi$-helices.

\begin{tabular}{|c|c|c|c|c|c|}
\hline Protein PDB ID & Chain/Residues & Length of Helix & Chirality Value & Chirality Sign & Protein Class \\
\hline $1 \mathrm{~A} 8 \mathrm{E}$ & $\mathrm{A} / 124-130$ & 7 & 0.1150 & Right-handed & Iron transport \\
\hline 1A8I & A/488-495 & 8 & 0.1632 & Right-handed & Transferase \\
\hline 1BDM & A/217-223 & 7 & 0.1350 & Right-handed & Oxidoreductase \\
\hline 1BG6 & A/297-303 & 7 & 0.1373 & Right-handed & Oxidoreductase \\
\hline 1D3G & A/37-43 & 7 & 0.1283 & Right-handed & Oxidoreductase \\
\hline 1DK8 & A/242-249 & 8 & 0.1711 & Right-handed & Signaling protein \\
\hline 1DYS & A/112-118 & 7 & 0.1250 & Right-handed & Hydrolase \\
\hline 1DZ4 & A/150-156 & 7 & 0.1273 & Right-handed & Oxidoreductase \\
\hline $1 \mathrm{E} 3 \mathrm{~A}$ & A/138-146 & 9 & 0.2050 & Right-handed & Hydrolase \\
\hline $1 \mathrm{EGU}$ & A/292-298 & 7 & 0.1323 & Right-handed & Lyase \\
\hline 1EGU & A/441- 447 & 7 & 0.1229 & Right-handed & Lyase \\
\hline 1EI5 & A/177-183 & 7 & 0.1299 & Right-handed & Hydrolase \\
\hline $1 \mathrm{EK} 6$ & A/105-111 & 7 & 0.1502 & Right-handed & Isomerase \\
\hline 1EL4 & $\mathrm{A} / 44-51$ & 8 & 0.1665 & Right-handed & Luminescent protein \\
\hline 1ELK & A/95-101 & 7 & 0.1421 & Right-handed & Endocytosis/Exocytosis \\
\hline $1 \mathrm{EOK}$ & A/111-118 & 8 & 0.1670 & Right-handed & Hydrolase \\
\hline $1 E V Y$ & A/257-263 & 7 & 0.1543 & Right-handed & Oxidoreductase \\
\hline $1 \mathrm{~F} 3 \mathrm{~A}$ & A/126-132 & 7 & 0.1235 & Right-handed & Transferase \\
\hline $1 \mathrm{~F} 24$ & A/214-220 & 7 & 0.1336 & Right-handed & Oxidoreductase \\
\hline 1FQA & A/279-285 & 7 & 0.1304 & Right-handed & Sugar binding protein \\
\hline 1KVE & B/177-183 & 7 & 0.1271 & Right-handed & Toxin \\
\hline $1 \mathrm{MRO}$ & A/313-324 & 12 & 0.2911 & Right-handed & Transferase \\
\hline 1MUC & A/70-76 & 7 & 0.1270 & Right-handed & Isomerase \\
\hline 1NCI & $\mathrm{A} / 40-46$ & 7 & 0.1125 & Right-handed & Cell adhesin protein \\
\hline 1QGW & C/105-111 & 7 & 0.1287 & Right-handed & Photosynthesis \\
\hline 1Q̈H3 & A/154-160 & 7 & 0.1316 & Right-handed & Hydrolase \\
\hline 1QH8 & A/63-72 & 10 & 0.2242 & Right-handed & Oxidoreductase \\
\hline 1QLM & A/88-94 & 7 & 0.1216 & Right-handed & Hydrolase \\
\hline 1QMG & A/349-355 & 7 & 0.1503 & Right-handed & Oxidoreductase \\
\hline 1QMG & A/490-502 & 13 & 0.3543 & Right-handed & Oxidoreductase \\
\hline 1SMD & A/27-33 & 7 & 0.1276 & Right-handed & Hydrolase \\
\hline 1SUR & A/131-137 & 7 & 0.1303 & Right-handed & Oxidoreductase \\
\hline $1 \mathrm{THG}$ & $\mathrm{A} / 424-430$ & 7 & 0.1360 & Right-handed & Hydrolase \\
\hline 2SCP & A/56-62 & 7 & 0.1344 & Right-handed & Binding protein \\
\hline $1 \mathrm{~B} 16$ & A/104-110 & 7 & 0.1277 & Right-handed & Oxidoreductase \\
\hline 1B25 & A/479-485 & 7 & 0.1247 & Right-handed & Oxidoreductase \\
\hline $1 \mathrm{BDB}$ & $\mathrm{A} / 112-118$ & 7 & 0.1379 & Right-handed & Oxidoreductase \\
\hline 1BXK & A/98-104 & 7 & 0.1439 & Right-handed & Lyase \\
\hline $1 \mathrm{C} 3 \mathrm{P}$ & A/97-103 & 7 & 0.1447 & Right-handed & Lyase \\
\hline $1 \mathrm{C} 3 \mathrm{~W}$ & A/213-219 & 7 & 0.1543 & Right-handed & Ion transport \\
\hline $1 \mathrm{C} 7 \mathrm{~S}$ & A/641-647 & 7 & 0.0941 & Right-handed & Hydrolase \\
\hline $1 \mathrm{C} 7 \mathrm{~S}$ & A/801-807 & 7 & 0.1273 & Right-handed & Hydrolase \\
\hline $1 \mathrm{CB} 8$ & A/267-273 & 7 & 0.1317 & Right-handed & Lyase \\
\hline $1 \mathrm{COJ}$ & A/26-33 & 8 & 0.1745 & Right-handed & Oxidoreductase \\
\hline $1 \mathrm{CXP}$ & C/291-297 & 7 & 0.1234 & Right-handed & Oxidoreductase \\
\hline 1CYD & A/104-110 & 7 & 0.1336 & Right-handed & Oxidoreductase \\
\hline 1D3Y & A/253-259 & 7 & 0.1317 & Right-handed & Isomerase \\
\hline 1D8D & A/343-349 & 7 & 0.1146 & Right-handed & Transferase \\
\hline 1DC1 & A/98-104 & 7 & 0.1341 & Right-handed & Hydrolase \\
\hline 1DEK & A/137-145 & 9 & 0.1858 & Right-handed & Transferase \\
\hline 1DJ0 & A/81-87 & 7 & 0.1546 & Right-handed & Lyase \\
\hline 1DOZ & A/265-274 & 10 & 0.2409 & Right-handed & Lyase \\
\hline 1DQA & A/733-740 & 8 & 0.1738 & Right-handed & Oxidoreductase \\
\hline 1DQS & A/142-148 & 7 & 0.1262 & Right-handed & Lyase \\
\hline 1DXR & $C / 277-283$ & 7 & 0.1231 & Right-handed & Photosynthesis \\
\hline 1DXR & $\mathrm{H} / 27-33$ & 7 & 0.1234 & Right-handed & Photosynthesis \\
\hline 1DXR & L/129-135 & 7 & 0.1276 & Right-handed & Photosynthesis \\
\hline 1DXR & M/156-162 & 7 & 0.1229 & Right-handed & Photosynthesis \\
\hline 1EA5 & A/396-402 & 7 & 0.1241 & Right-handed & Hydrolase \\
\hline 1EA5 & $\mathrm{A} / 522-528$ & 7 & 0.1313 & Right-handed & Hydrolase \\
\hline 1EWF & A/181-187 & 7 & 0.1379 & Right-handed & Antibiotic \\
\hline 1EYZ & A/119-125 & 7 & 0.1426 & Right-handed & Transferase \\
\hline $1 \mathrm{~F} 24$ & A/140-146 & 7 & 0.1259 & Right-handed & Oxidoreductase \\
\hline 1FDS & A/111-117 & 7 & 0.1373 & Right-handed & Oxidoreductase \\
\hline
\end{tabular}


Table A1. Cont.

\begin{tabular}{|c|c|c|c|c|c|}
\hline Protein PDB ID & Chain/Residues & Length of Helix & Chirality Value & Chirality Sign & Protein Class \\
\hline 1FP3 & A/273-279 & 7 & 0.1241 & Right-handed & Isomerase \\
\hline 1FRP & $\mathrm{A} / 276-282$ & 7 & 0.1304 & Right-handed & Hydrolase \\
\hline 1FSW & A/174-180 & 7 & 0.1318 & Right-handed & Hydrolase \\
\hline 1FUR & A/155-161 & 7 & 0.1348 & Right-handed & Hydrolase \\
\hline 1FUR & A/383-389 & 7 & 0.1302 & Right-handed & Hydrolase \\
\hline $1 G 8 K$ & A/181-187 & 7 & 0.1299 & Right-handed & Oxidoreductase \\
\hline $1 \mathrm{G} 8 \mathrm{~K}$ & $\mathrm{~A} / 242-248$ & 7 & 0.1418 & Right-handed & Oxidoreductase \\
\hline $1 \mathrm{GAI}$ & A/150-156 & 7 & 0.1346 & Right-handed & Hydrolase \\
\hline 1HFE & S/71-77 & 7 & 0.1228 & Right-handed & Oxidoreductase \\
\hline 1HVB & A/183-189 & 7 & 0.1282 & Right-handed & Hydrolase \\
\hline $1 \mathrm{IOH}$ & A/26-32 & 7 & 0.1402 & Right-handed & Oxidoreductase \\
\hline 1LML & A/155-161 & 7 & 0.1243 & Right-handed & Hydrolase \\
\hline 1LST & A/126-132 & 7 & 0.1449 & Right-handed & Amino-acid binding protein \\
\hline 1LST & A/165-171 & 7 & 0.1207 & Right-handed & Amino-acid binding protein \\
\hline $1 \mathrm{MTY}$ & B/140-150 & 11 & 0.2786 & Right-handed & Oxidoreductase \\
\hline $1 \mathrm{MTY}$ & B/297-304 & 8 & 0.1463 & Right-handed & Oxidoreductase \\
\hline $1 \mathrm{MTY}$ & D/185-191 & 7 & 0.1139 & Right-handed & Oxidoreductase \\
\hline $1 \mathrm{MTY}$ & $\mathrm{D} / 202-214$ & 13 & 0.3008 & Right-handed & Oxidoreductase \\
\hline $1 \mathrm{MTY}$ & $\mathrm{D} / 306-318$ & 13 & 0.3226 & Right-handed & Oxidoreductase \\
\hline $1 \mathrm{MTY}$ & $\mathrm{D} / 379-385$ & 7 & 0.1590 & Right-handed & Oxidoreductase \\
\hline $1 \mathrm{ONE}$ & $\mathrm{A} / 67-73$ & 7 & 0.1322 & Right-handed & Lyase \\
\hline $1 \mathrm{PHN}$ & A/107-113 & 7 & 0.1335 & Right-handed & Electron transport \\
\hline 1QOY & A/26-32 & 7 & 0.1315 & Right-handed & Toxin \\
\hline 1SVF & A/171-177 & 7 & 0.1381 & Right-handed & Viral protein \\
\hline 1UOK & A/393-399 & 7 & 0.1330 & Right-handed & Hydrolase \\
\hline 1YAC & A/114-120 & 7 & 0.1410 & Right-handed & Hydrolase \\
\hline 1YGE & A/261-267 & 7 & 0.1353 & Right-handed & Oxidoreductase \\
\hline 1YGE & A/494-506 & 13 & 0.3152 & Right-handed & Oxidoreductase \\
\hline 1YGE & A/684-690 & 7 & 0.1398 & Right-handed & Oxidoreductase \\
\hline $2 \mathrm{EBN}$ & A/257-263 & 7 & 0.1327 & Right-handed & Hydrolase \\
\hline 2HMQ & A/101-107 & 7 & 0.1429 & Right-handed & Oxygen transport \\
\hline 2OLB & A/301-308 & 8 & 0.1504 & Right-handed & Binding protein \\
\hline 4PAN & A/325-331 & 7 & 0.1580 & Right-handed & Signaling protein \\
\hline 5CSM & A/233-239 & 7 & 0.1380 & Right-handed & Isomerase \\
\hline 7A3H & A/146-152 & 7 & 0.1293 & Right-handed & Hydrolase \\
\hline 9GAF & A/186-192 & 7 & 0.1005 & Right-handed & Hydrolase \\
\hline
\end{tabular}

Table A2. The calculated parameters of $\alpha$-turns.

\begin{tabular}{|c|c|c|c|c|c|}
\hline Family or Group & Protein PDB ID & Chain/Residues & Chirality Value & Chirality Sign & Protein Class \\
\hline \multirow{29}{*}{$\mathrm{F} 1$} & 1AAP & A/24-28 & 0.0917 & Right-handed & Proteinase Inhibitor (Trypsin) \\
\hline & $1 \mathrm{ACX}$ & $\mathrm{A} / 82-86$ & 0.0735 & Right-handed & Antibacterial Protein \\
\hline & $2 \mathrm{AK} 3$ & A/149-153 & 0.0694 & Right-handed & Transferase (Phosphotransferase) \\
\hline & $3 \mathrm{COX}$ & $\mathrm{A} / 391-395$ & 0.0852 & Right-handed & Oxidoreductase (Oxygen Receptor) \\
\hline & 1DRF & A/152-156 & 0.0837 & Right-handed & Oxidoreductase (Ch-Nh(D)-Nad Or Nadp (A)) \\
\hline & 1ECA & $\mathrm{A} / 38-42$ & 0.0884 & Right-handed & Oxygen Transport \\
\hline & 1GD1 & $\mathrm{O} / 47-51$ & 0.0668 & Right-handed & Oxidoreductase (Aldehyde(D)-Nad (A)) \\
\hline & 1GOX & $\mathrm{A} / 345-349$ & 0.1173 & Right-handed & Oxidoreductase (Oxygen $(\mathrm{A}))$ \\
\hline & $1 \mathrm{MBA}$ & $\mathrm{A} / 43-47$ & 0.0861 & Right-handed & Oxygen Storage \\
\hline & 1OMD & $\mathrm{A} / 2-6$ & 0.0911 & Right-handed & Calcium Binding Protein \\
\hline & 1OVA & $\mathrm{A} / 277-281$ & 0.0764 & Right-handed & Serpin \\
\hline & 1OVA & $\mathrm{A} / 318-322$ & 0.1015 & Right-handed & Serpin \\
\hline & $1 \mathrm{RDG}$ & $\mathrm{A} / 6-10$ & 0.0552 & Right-handed & Electron Transfer (Iron-Sulfur Protein) \\
\hline & $1 R D G$ & $\mathrm{~A} / 14-18$ & 0.0976 & Right-handed & Electron Transfer (Iron-Sulfur Protein) \\
\hline & $1 R D G$ & $\mathrm{~A} / 39-43$ & 0.0585 & Right-handed & Electron Transfer (Iron-Sulfur Protein) \\
\hline & 2SN3 & $\mathrm{A} / 7-11$ & 0.0626 & Right-handed & Toxin \\
\hline & 2SN4 & $\mathrm{A} / 31-35$ & 0.0847 & Right-handed & Toxin \\
\hline & 1THB & $\mathrm{A} / 113-117$ & 0.0937 & Right-handed & Oxygen Transport \\
\hline & $2 \mathrm{ACT}$ & $\mathrm{A} / 85-89$ & 0.1009 & Right-handed & Hydrolase (Proteinase) \\
\hline & 2AZA & $\mathrm{A} / 40-44$ & 0.0952 & Right-handed & Electron Transport Protein (Cuproprotein) \\
\hline & $2 \mathrm{CA} 2$ & $\mathrm{~A} / 34-38$ & 0.1028 & Right-handed & Lyase (Oxo-Acid) \\
\hline & $2 \mathrm{CPP}$ & $\mathrm{A} / 77-81$ & 0.0883 & Right-handed & Oxidoreductase (Oxygenase) \\
\hline & $2 \mathrm{CPP}$ & $\mathrm{A} / 328-332$ & 0.1000 & Right-handed & Oxidoreductase (Oxygenase) \\
\hline & $2 \mathrm{CSC}$ & $\mathrm{A} / 59-63$ & 0.0674 & Right-handed & Lyase \\
\hline & $2 \mathrm{CYP}$ & $\mathrm{A} / 58-62$ & 0.0673 & Right-handed & Oxidoreductase (H2O2(A)) \\
\hline & 2ER7 & $\mathrm{E} / 240-244$ & 0.0926 & Right-handed & Hydrolase/Hydrolase Inhibitor \\
\hline & 2FCR & A/94-98 & 0.0923 & Right-handed & Electron Transport \\
\hline & $2 \mathrm{FCR}$ & $\mathrm{A} / 148-152$ & 0.0841 & Right-handed & Electron Transport \\
\hline & 2LTN & $\mathrm{A} / 54-58$ & 0.0776 & Right-handed & Lectin \\
\hline
\end{tabular}


Table A2. Cont.

\begin{tabular}{|c|c|c|c|c|c|}
\hline Family or Group & Protein PDB ID & Chain/Residues & Chirality Value & Chirality Sign & Protein Class \\
\hline & 2LTN & $\mathrm{A} / 125-129$ & 0.0523 & Right-handed & Lectin \\
\hline & $2 \mathrm{LTN}$ & $\mathrm{A} / 167-171$ & 0.0852 & Right-handed & Lectin \\
\hline & 2RHE & A/93-97 & 0.0986 & Right-handed & Immunoglobulin \\
\hline & 2RSP & $\mathrm{A} / 46-50$ & 0.1031 & Right-handed & Hydrolase (Aspartyl Proteinase) \\
\hline & 2RSP & $\mathrm{A} / 219-223$ & 0.0798 & Right-handed & Hydrolase (Serine Proteinase) \\
\hline & $2 \mathrm{TRX}$ & $\mathrm{A} / 59-63$ & 0.0993 & Right-handed & Electron Transport \\
\hline & 3BLM & $\mathrm{A} / 50-54$ & 0.0742 & Right-handed & Hydrolase \\
\hline & 3CLA & A/97-101 & 0.0833 & Right-handed & Transferase (Acyltransferase) \\
\hline & 3CLA & A/194-198 & 0.0880 & Right-handed & Transferase (Acyltransferase) \\
\hline & $4 \mathrm{FGF}$ & A/67-71 & 0.0920 & Right-handed & Growth Factor \\
\hline & 3GRS & A/164-168 & 0.0968 & Right-handed & Oxidoreductase (Flavoenzyme) \\
\hline & 4ENL & A/102-106 & 0.0738 & Right-handed & Carbon-Oxygen Lyase \\
\hline & 5FD1 & A/35-39 & 0.0986 & Right-handed & Electron Transport(Iron-Sulfur) \\
\hline & $5 \mathrm{CPA}$ & $\mathrm{A} / 3-7$ & 0.1063 & Right-handed & Hydrolase (C-Terminal Peptidase) \\
\hline & $5 \mathrm{CPA}$ & A/29-33 & 0.0905 & Right-handed & Hydrolase (C-Terminal Peptidase) \\
\hline & $5 \mathrm{P} 21$ & $\mathrm{~A} / 145-149$ & 0.0840 & Right-handed & Oncogene Protein \\
\hline & $6 \mathrm{LDH}$ & $\mathrm{A} / 181-185$ & 0.1114 & Right-handed & Oxidoreductase(Choh(D)-Nad(A)) \\
\hline \multirow{8}{*}{ F2 } & $2 \mathrm{AK} 3$ & A/137-141 & 0.0723 & Right-handed & Transferase (Phosphotransferase) \\
\hline & $3 \mathrm{COX}$ & $\mathrm{A} / 453-457$ & 0.0649 & Right-handed & Oxidoreductase (Oxygen Receptor) \\
\hline & 1FKF & A/87-91 & 0.0400 & Right-handed & Isomerase \\
\hline & 1GD1 & $\mathrm{O} / 129-133$ & 0.0791 & Right-handed & Oxidoreductase (Aldehyde(D)-Nad(A)) \\
\hline & 1GD2 & $\mathrm{O} / 267-271$ & 0.0761 & Right-handed & Oxidoreductase (Aldehyde(D)-Nad(A)) \\
\hline & $2 \mathrm{TEC}$ & $\mathrm{E} / 261-265$ & 0.0750 & Right-handed & Complex(Serine Proteinase-Inhibitor) \\
\hline & $2 \mathrm{TRX}$ & A/49-53 & 0.0799 & Right-handed & Electron Transport \\
\hline & $5 \mathrm{CPA}$ & A/89-93 & 0.0664 & Right-handed & Hydrolase (C-Terminal Peptidase) \\
\hline \multirow{5}{*}{ g1 } & 4GCR & A/47-51 & -0.0291 & Left-handed & Eye Lens Protein \\
\hline & 4GCR & $\mathrm{A} / 136-140$ & -0.0283 & Left-handed & Eye Lens Protein \\
\hline & $2 \mathrm{CYP}$ & $\mathrm{A} / 35-39$ & -0.0422 & Left-handed & Oxidoreductase (H2O2(A)) \\
\hline & 2FBJ & $\mathrm{A} / 48-52$ & -0.0411 & Left-handed & Immunoglobulin \\
\hline & 2PRK & $\mathrm{A} / 212-216$ & -0.0230 & Left-handed & Serine Proteinase \\
\hline \multirow{2}{*}{ g2 } & $2 \mathrm{FBJ}$ & $\mathrm{H} / 100-104$ & -0.0355 & Left-handed & Immunoglobulin \\
\hline & 2RHE & $\mathrm{A} / 50-54$ & -0.0478 & Left-handed & Immunoglobulin \\
\hline \multirow{4}{*}{ g3 } & $1 \mathrm{FKF}$ & $\mathrm{A} / 82-86$ & 0.0384 & Right-handed & Isomerase \\
\hline & 1OVA & $\mathrm{A} / 69-73$ & 0.0523 & Right-handed & Serpin \\
\hline & 3GRS & $\mathrm{A} / 55-59$ & 0.0351 & Right-handed & Oxidoreductase (Flavoenzyme) \\
\hline & $4 \mathrm{BP} 2$ & $\mathrm{~A} / 25-29$ & -0.0123 & Left-handed & Carboxylic Ester Hydrolase Zymogen \\
\hline \multirow{4}{*}{$\mathrm{g} 4$} & $2 \mathrm{ACT}$ & A/188-192 & -0.0636 & Left-handed & Hydrolase (Proteinase) \\
\hline & 2LZM & $\mathrm{A} / 27-31$ & -0.0613 & Left-handed & Hydrolase (O-Glycosyl) \\
\hline & 3APR & $\mathrm{E} / 11-15$ & -0.0684 & Left-handed & Hydrolase/Hydrolase Inhibitor \\
\hline & 2FOX & $\mathrm{A} / 56-60$ & -0.0741 & Left-handed & Electron Transport \\
\hline \multirow{3}{*}{ g5 } & $1 \mathrm{FX} 1$ & $\mathrm{~A} / 71-75$ & 0.1042 & Right-handed & Electron Transfer (Flavoprotein) \\
\hline & 1YPI & A/25-29 & 0.1020 & Right-handed & Isomerase (Intramolecular Oxidoreductase) \\
\hline & $2 \mathrm{FOX}$ & $\mathrm{A} / 40-44$ & 0.1004 & Right-handed & Electron Transport \\
\hline \multirow{3}{*}{ g6 } & 1GD1 & $\mathrm{O} / 300-304$ & -0.0084 & Left-handed & Oxidoreductase (Aldehyde(D)-Nad(A)) \\
\hline & 2LTN & $\mathrm{A} / 100-104$ & -0.0026 & Left-handed & Lectin \\
\hline & 4PEP & A/9-13 & -0.0003 & Left-handed & Hydrolase (Acid Proteinase) \\
\hline \multirow{2}{*}{ g7 } & $2 \mathrm{AK} 3$ & A/129-133 & 0.0784 & Right-handed & Transferase (Phosphotransferase) \\
\hline & $1 \mathrm{FX} 1$ & $\mathrm{~A} / 72-76$ & 0.1092 & Right-handed & Electron Transfer (Flavoprotein) \\
\hline \multirow{2}{*}{ Other } & $1 \mathrm{RBP}$ & A/63-67 & -0.0099 & Left-handed & Retinol Transport \\
\hline & $2 \mathrm{FBJ}$ & $\mathrm{L} / 166-170$ & 0.0745 & Right-handed & Immunoglobulin \\
\hline
\end{tabular}

Table A3. The calculated parameters of $\Omega$-loops.

\begin{tabular}{ccccc}
\hline Protein PDB ID & Chain/Residues & Length of Loop & Chirality Value & Chirality Sign \\
\hline 1ABE & A/93-99 & 7 & -0.0280 & Left-handed \\
1ABE & A/142-148 & 7 & 0.1496 & Right-handed \\
1ABE & A/203-208 & 6 & 0.0231 & Right-handed \\
1ABE & A/236-248 & 13 & 0.1632 & Right-handed \\
1ABE & A/289-294 & 6 & 0.0232 & Right-handed \\
1ABE & A/299-304 & 6 & 0.0464 & Right-handed \\
ACT & A/8-13 & 6 & 0.0508 & Right-handed \\
ACT & A/58-64 & 7 & 0.0462 & Right-handed \\
ACT & A/89-103 & 15 & -0.1453 & Left-handed \\
ACT & A/139-144 & 6 & 0.0709 & Right-handed \\
ACT & A/141-156 & 16 & 0.1703 & Right-handed \\
ACT & A/182-192 & 11 & 0.0027 & Right-handed \\
ACT & A/198-205 & 8 & -0.0151 & Left-handed \\
ACT & A/203-209 & 7 & -0.0605 & Left-handed \\
\hline
\end{tabular}


Table A3. Cont.

\begin{tabular}{|c|c|c|c|c|c|}
\hline Protein PDB ID & Chain/Residues & Length of Loop & Chirality Value & Chirality Sign & Protein Class \\
\hline $8 \mathrm{ADH}$ & $\mathrm{A} / 14-21$ & 8 & -0.0071 & Left-handed & Oxidoreductase (Nad(A)-Choh(D)) \\
\hline $8 \mathrm{ADH}$ & $\mathrm{A} / 100-112$ & 13 & 0.3005 & Right-handed & Oxidoreductase (Nad(A)-Choh(D)) \\
\hline $8 \mathrm{ADH}$ & $\mathrm{A} / 115-122$ & 8 & -0.0038 & Left-handed & Oxidoreductase (Nad(A)-Choh(D)) \\
\hline $8 \mathrm{ADH}$ & $\mathrm{A} / 122-128$ & 7 & -0.0191 & Left-handed & Oxidoreductase (Nad(A)-Choh(D)) \\
\hline $8 \mathrm{ADH}$ & $\mathrm{A} / 282-287$ & 6 & 0.0022 & Right-handed & Oxidoreductase (Nad(A)-Choh(D)) \\
\hline $3 \mathrm{ADK}$ & A/133-142 & 10 & 0.0617 & Right-handed & Transferase(Phosphotransferase) \\
\hline 2ALP & $\mathrm{A} / 217-224$ & 8 & -0.0460 & Left-handed & Hydrolase (Serine Proteinase) \\
\hline 3APP & $\mathrm{A} / 41-55$ & 15 & 0.2606 & Right-handed & Hydrolase (Acid Proteinase) \\
\hline 3APP & A/129-136 & 8 & 0.0022 & Right-handed & Hydrolase (Acid Proteinase) \\
\hline 3APP & A/139-149 & 11 & 0.4213 & Right-handed & Hydrolase (Acid Proteinase) \\
\hline 3APP & A/184-192 & 9 & 0.0463 & Right-handed & Hydrolase (Acid Proteinase) \\
\hline 2APR & $\mathrm{A} / 8-17$ & 10 & -0.1572 & Left-handed & Hydrolase (Aspartic Proteinase) \\
\hline 2APR & $\mathrm{A} / 18-31$ & 14 & -0.2057 & Left-handed & Hydrolase (Aspartic Proteinase) \\
\hline 2APR & $\mathrm{A} / 43-58$ & 16 & 0.0879 & Right-handed & Hydrolase (Aspartic Proteinase) \\
\hline 2APR & $\mathrm{A} / 61-69$ & 9 & 0.1019 & Right-handed & Hydrolase (Aspartic Proteinase) \\
\hline 2APR & $\mathrm{A} / 76-83$ & 8 & -0.0071 & Left-handed & Hydrolase (Aspartic Proteinase) \\
\hline 2APR & A/90-103 & 14 & -0.1480 & Left-handed & Hydrolase (Aspartic Proteinase) \\
\hline $2 \mathrm{APR}$ & $\mathrm{A} / 129-138$ & 10 & 0.0383 & Right-handed & Hydrolase (Aspartic Proteinase) \\
\hline 2APR & A/189-197 & 9 & 0.0337 & Right-handed & Hydrolase (Aspartic Proteinase) \\
\hline 2APR & A/203-211 & 9 & -0.0328 & Left-handed & Hydrolase (Aspartic Proteinase) \\
\hline 2APR & $\mathrm{A} / 216-226$ & 11 & 0.0677 & Right-handed & Hydrolase (Aspartic Proteinase) \\
\hline 2APR & $\mathrm{A} / 227-232$ & 6 & 0.1507 & Right-handed & Hydrolase (Aspartic Proteinase) \\
\hline 2APR & $\mathrm{A} / 233-248$ & 16 & 0.0514 & Right-handed & Hydrolase (Aspartic Proteinase) \\
\hline 2APR & $\mathrm{A} / 243-250$ & 8 & -0.0071 & Left-handed & Hydrolase (Aspartic Proteinase) \\
\hline 2APR & $\mathrm{A} / 261-273$ & 13 & -0.1703 & Left-handed & Hydrolase (Aspartic Proteinase) \\
\hline 2APR & $\mathrm{A} / 280-287$ & 8 & -0.0761 & Left-handed & Hydrolase (Aspartic Proteinase) \\
\hline 2APR & A/291-299 & 9 & -0.0724 & Left-handed & Hydrolase (Aspartic Proteinase) \\
\hline 1AZU & A/9-15 & 7 & -0.0069 & Left-handed & Electron Transport (Copper Binding) \\
\hline 1AZU & $\mathrm{A} / 35-46$ & 12 & 0.0569 & Right-handed & Electron Transport (Copper Binding) \\
\hline 1AZU & $\mathrm{A} / 67-72$ & 6 & 0.0376 & Right-handed & Electron Transport (Copper Binding) \\
\hline 1AZU & $\mathrm{A} / 73-83$ & 11 & 0.0646 & Right-handed & Electron Transport (Copper Binding) \\
\hline 1AZU & $\mathrm{A} / 84-92$ & 9 & -0.0023 & Left-handed & Electron Transport (Copper Binding) \\
\hline 1AZU & A/112-118 & 7 & 0.0420 & Right-handed & Electron Transport (Copper Binding) \\
\hline $1 \mathrm{CYO}$ & $\mathrm{A} / 32-47$ & 16 & 0.4146 & Right-handed & Electron Transport \\
\hline 1BP2 & $\mathrm{A} / 23-30$ & 8 & 0.0360 & Right-handed & Hydrolase \\
\hline 1BP3 & $\mathrm{A} / 25-39$ & 15 & -0.0675 & Left-handed & Hydrolase \\
\hline $1 \mathrm{BP} 4$ & $A / 56-66$ & 11 & 0.2318 & Right-handed & Hydrolase \\
\hline 2BP2 & $\mathrm{A} / 23-30$ & 8 & 0.0360 & Right-handed & Hydrolase Zymogen \\
\hline 2BP3 & $\mathrm{A} / 25-39$ & 15 & -0.0675 & Left-handed & Hydrolase Zymogen \\
\hline 2BP4 & $\mathrm{A} / 61-68$ & 8 & -0.0056 & Left-handed & Hydrolase Zymogen \\
\hline $256 \mathrm{~B}$ & $\mathrm{~A} / 16-25$ & 10 & 0.1574 & Right-handed & Electron Transport \\
\hline $256 \mathrm{~B}$ & $\mathrm{~A} / 47-58$ & 12 & 0.1626 & Right-handed & Electron Transport \\
\hline $351 C$ & $\mathrm{~A} / 16-25$ & 10 & -0.0117 & Left-handed & Electron Transport \\
\hline $351 C$ & $\mathrm{~A} / 51-62$ & 12 & 0.0243 & Right-handed & Electron Transport \\
\hline $155 C$ & $\mathrm{~A} / 21-28$ & 8 & -0.1010 & Left-handed & Electron Transport \\
\hline $155 C$ & $\mathrm{~A} / 47-54$ & 8 & 0.0381 & Right-handed & Electron Transport \\
\hline $155 C$ & A/83-95 & 13 & 0.3003 & Right-handed & Electron Transport \\
\hline $155 C$ & $\mathrm{~A} / 128-133$ & 6 & 0.0115 & Right-handed & Electron Transport \\
\hline $2 \mathrm{C} 2 \mathrm{C}$ & $\mathrm{A} / 18-33$ & 16 & -0.2105 & Left-handed & Electron Transport Protein (Cytochrome) \\
\hline $2 \mathrm{C} 2 \mathrm{C}$ & $\mathrm{A} / 30-43$ & 14 & 0.1534 & Right-handed & Electron Transport Protein (Cytochrome) \\
\hline $2 \mathrm{C} 2 \mathrm{C}$ & $\mathrm{A} / 41-56$ & 16 & 0.2603 & Right-handed & Electron Transport Protein (Cytochrome) \\
\hline $2 \mathrm{C} 2 \mathrm{C}$ & $\mathrm{A} / 74-89$ & 16 & 0.4033 & Right-handed & Electron Transport Protein (Cytochrome) \\
\hline $2 \mathrm{CAB}$ & $\mathrm{A} / 6-12$ & 7 & 0.0716 & Right-handed & Hydro-Lyase \\
\hline $2 \mathrm{CAB}$ & $\mathrm{A} / 17-24$ & 8 & 0.1911 & Right-handed & Hydro-Lyase \\
\hline $2 \mathrm{CAB}$ & $\mathrm{A} / 78-87$ & 10 & 0.1359 & Right-handed & Hydro-Lyase \\
\hline $2 \mathrm{CAB}$ & A/98-104 & 7 & 0.0950 & Right-handed & Hydro-Lyase \\
\hline $2 \mathrm{CAB}$ & A/108-114 & 7 & -0.0536 & Left-handed & Hydro-Lyase \\
\hline $2 \mathrm{CAB}$ & $\mathrm{A} / 128-140$ & 13 & 0.2908 & Right-handed & Hydro-Lyase \\
\hline $2 \mathrm{CAB}$ & A/197-204 & 8 & -0.0225 & Left-handed & Hydro-Lyase \\
\hline $2 \mathrm{CAB}$ & $\mathrm{A} / 230-240$ & 11 & -0.0683 & Left-handed & Hydro-Lyase \\
\hline 1CA2 & A/5-16 & 12 & 0.1204 & Right-handed & Lyase (Oxo-Acid) \\
\hline $1 \mathrm{CA} 3$ & $\mathrm{~A} / 17-23$ & 7 & 0.1274 & Right-handed & Lyase (Oxo-Acid) \\
\hline 1CA4 & A/98-103 & 6 & 0.0470 & Right-handed & Lyase (Oxo-Acid) \\
\hline 1CA5 & $\mathrm{A} / 108-114$ & 7 & -0.0629 & Left-handed & Lyase (Oxo-Acid) \\
\hline 1CA6 & $\mathrm{A} / 128-140$ & 13 & 0.3094 & Right-handed & Lyase (Oxo-Acid) \\
\hline 1CA7 & A/166-172 & 7 & 0.0573 & Right-handed & Lyase (Oxo-Acid) \\
\hline
\end{tabular}


Table A3. Cont.

\begin{tabular}{|c|c|c|c|c|c|}
\hline Protein PDB ID & Chain/Residues & Length of Loop & Chirality Value & Chirality Sign & Protein Class \\
\hline $1 \mathrm{CA} 8$ & A/197-204 & 8 & -0.0111 & Left-handed & Lyase (Oxo-Acid) \\
\hline 1CA9 & $\mathrm{A} / 232-239$ & 8 & -0.0806 & Left-handed & Lyase (Oxo-Acid) \\
\hline $2 \mathrm{CHA}$ & B/70-78 & 9 & 0.0557 & Right-handed & Hydrolase (Serine Proteinase) \\
\hline $2 \mathrm{CHA}$ & B/94-102 & 9 & 0.0806 & Right-handed & Hydrolase (Serine Proteinase) \\
\hline $2 \mathrm{CHA}$ & $\mathrm{B} / 114-119$ & 6 & 0.0369 & Right-handed & Hydrolase (Serine Proteinase) \\
\hline $2 \mathrm{CHA}$ & $\mathrm{C} / 217-224$ & 8 & -0.0060 & Left-handed & Hydrolase (Serine Proteinase) \\
\hline $3 \mathrm{CNA}$ & $\mathrm{A} / 13-21$ & 9 & 0.0381 & Right-handed & Lectin (Agglutinin) \\
\hline $3 \mathrm{CNA}$ & A/97-104 & 8 & -0.0102 & Left-handed & Lectin (Agglutinin) \\
\hline $3 \mathrm{CNA}$ & A/116-123 & 8 & 0.0756 & Right-handed & Lectin (Agglutinin) \\
\hline $3 \mathrm{CNA}$ & $\mathrm{A} / 147-155$ & 9 & 0.0144 & Right-handed & Lectin (Agglutinin) \\
\hline $3 \mathrm{CNA}$ & $\mathrm{A} / 160-165$ & 6 & 0.0127 & Right-handed & Lectin (Agglutinin) \\
\hline $3 \mathrm{CNA}$ & A/199-209 & 11 & 0.0003 & Right-handed & Lectin (Agglutinin) \\
\hline $3 \mathrm{CNA}$ & $\mathrm{A} / 222-235$ & 14 & 0.1464 & Right-handed & Lectin (Agglutinin) \\
\hline $3 \mathrm{CNA}$ & $\mathrm{A} / 229-237$ & 9 & 0.0108 & Right-handed & Lectin (Agglutinin) \\
\hline 3СРA & $\mathrm{A} / 128-141$ & 14 & 0.0767 & Right-handed & Hydrolase (C-Terminal Peptidase) \\
\hline $3 \mathrm{CPA}$ & A/142-156 & 15 & 0.2551 & Right-handed & Hydrolase (C-Terminal Peptidase) \\
\hline 3CPA & A/156-166 & 11 & 0.1575 & Right-handed & Hydrolase (C-Terminal Peptidase) \\
\hline 3CPA & $\mathrm{A} / 205-213$ & 9 & 0.0898 & Right-handed & Hydrolase (C-Terminal Peptidase) \\
\hline 3СРА & $\mathrm{A} / 231-237$ & 7 & -0.0073 & Left-handed & Hydrolase (C-Terminal Peptidase) \\
\hline 3СРA & $\mathrm{A} / 244-250$ & 7 & -0.0284 & Left-handed & Hydrolase (C-Terminal Peptidase) \\
\hline 3СРA & $\mathrm{A} / 272-285$ & 14 & -0.0102 & Left-handed & Hydrolase (C-Terminal Peptidase) \\
\hline $5 \mathrm{CPV}$ & $\mathrm{A} / 18-23$ & 6 & 0.0092 & Right-handed & Calcium Binding \\
\hline $5 \mathrm{CPV}$ & $\mathrm{A} / 64-77$ & 14 & 0.2505 & Right-handed & Calcium Binding \\
\hline $1 C R N$ & $\mathrm{~A} / 33-44$ & 12 & -0.0524 & Left-handed & Plant Protein \\
\hline 1CTX & $\mathrm{A} / 1-15$ & 15 & 0.0597 & Right-handed & Toxin \\
\hline 1CTX & $\mathrm{A} / 26-35$ & 10 & 0.1348 & Right-handed & Toxin \\
\hline $1 C Y C$ & $\mathrm{~A} / 18-32$ & 15 & -0.1967 & Left-handed & Electron Transport \\
\hline $1 C Y C$ & $\mathrm{~A} / 30-43$ & 14 & 0.0486 & Right-handed & Electron Transport \\
\hline $1 C Y C$ & $\mathrm{~A} / 40-54$ & 15 & 0.1398 & Right-handed & Electron Transport \\
\hline $1 C Y C$ & $\mathrm{~A} / 70-84$ & 15 & 0.1522 & Right-handed & Electron Transport \\
\hline $3 \mathrm{CYT}$ & $\mathrm{O} / 18-32$ & 15 & -0.1637 & Left-handed & Electron Transport (Heme Protein) \\
\hline 3CYT & $\mathrm{O} / 34-43$ & 10 & 0.1153 & Right-handed & Electron Transport (Heme Protein) \\
\hline 3CYT & $\mathrm{O} / 40-54$ & 15 & 0.1250 & Right-handed & Electron Transport (Heme Protein) \\
\hline $3 \mathrm{CYT}$ & $\mathrm{O} / 70-84$ & 15 & 0.2509 & Right-handed & Electron Transport (Heme Protein) \\
\hline $1 \mathrm{ECD}$ & $\mathrm{A} / 33-42$ & 10 & 0.3042 & Right-handed & Oxygen Transport \\
\hline $1 \mathrm{ECD}$ & $\mathrm{A} / 41-49$ & 9 & 0.0899 & Right-handed & Oxygen Transport \\
\hline 1EST & $\mathrm{A} / 69-80$ & 12 & 0.0984 & Right-handed & Hydrolase \\
\hline $1 \mathrm{EST}$ & A/94-104 & 11 & 0.1166 & Right-handed & Hydrolase \\
\hline $1 \mathrm{EST}$ & A/112-118 & 7 & -0.0091 & Left-handed & Hydrolase \\
\hline $1 \mathrm{EST}$ & $\mathrm{A} / 165-178$ & 14 & 0.3179 & Right-handed & Hydrolase \\
\hline $1 \mathrm{EST}$ & $\mathrm{A} / 216-226$ & 11 & 0.0211 & Right-handed & Hydrolase \\
\hline 7FAB & L/24-29 & 6 & 0.0311 & Right-handed & Immune System \\
\hline 7FAB & $\mathrm{L} / 122-132$ & 11 & -0.0979 & Left-handed & Immune System \\
\hline 7FAB & $\mathrm{L} / 168-173$ & 6 & -0.0200 & Left-handed & Immune System \\
\hline 7FAB & $\mathrm{L} / 182-187$ & 6 & 0.0160 & Right-handed & Immune System \\
\hline 7FAB & $\mathrm{H} / 72-77$ & 6 & 0.0406 & Right-handed & Immune System \\
\hline 7FAB & H/99-105 & 7 & -0.0067 & Left-handed & Immune System \\
\hline 1DUR & $\mathrm{A} / 12-23$ & 12 & 0.2808 & Right-handed & Electron Transport \\
\hline 1DUR & $\mathrm{A} / 30-41$ & 12 & 0.0120 & Right-handed & Electron Transport \\
\hline 1DUR & $\mathrm{A} / 39-50$ & 12 & 0.2652 & Right-handed & Electron Transport \\
\hline 5NLL & $\mathrm{A} / 54-61$ & 8 & -0.0590 & Left-handed & Electron Transport \\
\hline $2 \mathrm{GCH}$ & $\mathrm{F} / 70-78$ & 9 & 0.1866 & Right-handed & Hydrolase (Serine Proteinase) \\
\hline $2 \mathrm{GCH}$ & F/94-101 & 8 & 0.0378 & Right-handed & Hydrolase (Serine Proteinase) \\
\hline $2 \mathrm{GCH}$ & $\mathrm{F} / 112-118$ & 7 & -0.0220 & Left-handed & Hydrolase (Serine Proteinase) \\
\hline $2 \mathrm{GCH}$ & G/165-176 & 12 & 0.3527 & Right-handed & Hydrolase (Serine Proteinase) \\
\hline $2 \mathrm{GCH}$ & $\mathrm{G} / 217-224$ & 8 & -0.0086 & Left-handed & Hydrolase (Serine Proteinase) \\
\hline 1GPD & G/47-52 & 6 & 0.0284 & Right-handed & Oxidoreductase \\
\hline 1GPD & G/76-82 & 7 & 0.0872 & Right-handed & Oxidoreductase \\
\hline 1GPD & G/121-129 & 9 & 0.0052 & Right-handed & Oxidoreductase \\
\hline 1GPD & G/183-198 & 16 & -0.1486 & Left-handed & Oxidoreductase \\
\hline 3GRS & A/83-89 & 7 & -0.0102 & Left-handed & Oxidoreductase (Flavoenzyme) \\
\hline 3GRS & A/139-147 & 9 & -0.0760 & Left-handed & Oxidoreductase (Flavoenzyme) \\
\hline 3GRS & $\mathrm{A} / 162-172$ & 11 & 0.0576 & Right-handed & Oxidoreductase (Flavoenzyme) \\
\hline 3GRS & $\mathrm{A} / 239-245$ & 7 & -0.0094 & Left-handed & Oxidoreductase (Flavoenzyme) \\
\hline 3GRS & $\mathrm{A} / 256-261$ & 6 & -0.0633 & Left-handed & Oxidoreductase (Flavoenzyme) \\
\hline 3GRS & $\mathrm{A} / 268-274$ & 7 & -0.0219 & Left-handed & Oxidoreductase (Flavoenzyme) \\
\hline
\end{tabular}


Table A3. Cont.

\begin{tabular}{|c|c|c|c|c|c|}
\hline Protein PDB ID & Chain/Residues & Length of Loop & Chirality Value & Chirality Sign & Protein Class \\
\hline 3GRS & $\mathrm{A} / 300-307$ & 8 & -0.0017 & Left-handed & Oxidoreductase (Flavoenzyme) \\
\hline 3GRS & $\mathrm{A} / 315-320$ & 6 & -0.0687 & Left-handed & Oxidoreductase (Flavoenzyme) \\
\hline 3GRS & $\mathrm{A} / 331-337$ & 7 & 0.0505 & Right-handed & Oxidoreductase (Flavoenzyme) \\
\hline 3GRS & A/404-415 & 12 & 0.2396 & Right-handed & Oxidoreductase (Flavoenzyme) \\
\hline 3GRS & $\mathrm{A} / 465-472$ & 8 & 0.0467 & Right-handed & Oxidoreductase (Flavoenzyme) \\
\hline $1 \mathrm{HIP}$ & A/20-26 & 7 & 0.1417 & Right-handed & Electron Transfer (Iron-Sulfur Protein) \\
\hline $1 \mathrm{HIP}$ & $\mathrm{A} / 28-41$ & 14 & 0.0932 & Right-handed & Electron Transfer (Iron-Sulfur Protein) \\
\hline $1 \mathrm{HIP}$ & $\mathrm{A} / 43-49$ & 7 & 0.0998 & Right-handed & Electron Transfer (Iron-Sulfur Protein) \\
\hline $1 \mathrm{HIP}$ & $\mathrm{A} / 44-59$ & 16 & 0.1820 & Right-handed & Electron Transfer (Iron-Sulfur Protein) \\
\hline $6 \mathrm{LDH}$ & $\mathrm{A} / 173-188$ & 16 & 0.2820 & Right-handed & Oxidoreductase (Choh(D)-Nad(A)) \\
\hline $6 \mathrm{LDH}$ & A/192-200 & 9 & 0.0461 & Right-handed & Oxidoreductase (Choh(D)-Nad(A)) \\
\hline $6 \mathrm{LDH}$ & $\mathrm{A} / 203-218$ & 16 & 0.0187 & Right-handed & Oxidoreductase (Choh(D)-Nad(A)) \\
\hline $6 \mathrm{LDH}$ & $\mathrm{A} / 212-225$ & 14 & 0.1010 & Right-handed & Oxidoreductase (Choh(D)-Nad(A)) \\
\hline $6 \mathrm{LDH}$ & $\mathrm{A} / 219-226$ & 8 & 0.1033 & Right-handed & Oxidoreductase (Choh(D)-Nad(A)) \\
\hline $6 \mathrm{LDH}$ & $\mathrm{A} / 239-246$ & 8 & -0.0174 & Left-handed & Oxidoreductase (Choh(D)-Nad(A)) \\
\hline $6 \mathrm{LDH}$ & $\mathrm{A} / 275-285$ & 11 & 0.0584 & Right-handed & Oxidoreductase (Choh(D)-Nad(A)) \\
\hline 1LH1 & $\mathrm{A} / 41-53$ & 13 & 0.3229 & Right-handed & Oxygen Transport \\
\hline 1LH2 & $\mathrm{A} / 47-54$ & 8 & 0.0285 & Right-handed & Oxygen Transport \\
\hline 2LHB & $\mathrm{A} / 46-59$ & 14 & 0.5669 & Right-handed & Oxygen Transport \\
\hline 2LHB & $\mathrm{A} / 55-64$ & 10 & 0.2227 & Right-handed & Oxygen Transport \\
\hline 7LYZ & $\mathrm{A} / 18-25$ & 8 & -0.0331 & Left-handed & Hydrolase (O-Glycosyl) \\
\hline $7 \mathrm{LYZ}$ & $\mathrm{A} / 36-42$ & 7 & 0.0318 & Right-handed & Hydrolase (O-Glycosyl) \\
\hline 7LYZ & $\mathrm{A} / 44-52$ & 9 & -0.0407 & Left-handed & Hydrolase (O-Glycosyl) \\
\hline 7LYZ & $\mathrm{A} / 60-75$ & 16 & 0.1404 & Right-handed & Hydrolase (O-Glycosyl) \\
\hline 2LZM & A/134-139 & 6 & 0.0657 & Right-handed & Hydrolase (O-Glycosyl) \\
\hline $1 \mathrm{MBN}$ & $\mathrm{A} / 40-47$ & 8 & 0.2021 & Right-handed & Oxygen Storage \\
\hline 1MBS & $\mathrm{A} / 37-50$ & 14 & 0.5199 & Right-handed & Oxygen Transport \\
\hline 1MBS & $\mathrm{A} / 49-54$ & 6 & 0.0358 & Right-handed & Oxygen Transport \\
\hline 1MBS & $\mathrm{A} / 78-84$ & 7 & 0.1077 & Right-handed & Oxygen Transport \\
\hline 2MHB & $\mathrm{A} / 40-48$ & 9 & 0.2250 & Right-handed & Oxygen Transport \\
\hline 2MHB & B/39-54 & 16 & 0.4710 & Right-handed & Oxygen Transport \\
\hline 2MHB & $\mathrm{B} / 47-57$ & 11 & 0.2937 & Right-handed & Oxygen Transport \\
\hline $1 N X B$ & $\mathrm{~A} / 6-13$ & 8 & -0.1576 & Left-handed & Neurotoxin (Post-Synaptic) \\
\hline $2 \mathrm{PAB}$ & $\mathrm{A} / 49-54$ & 6 & -0.0652 & Left-handed & Transport (Thyroxine,Retinol) In Serum \\
\hline 9PAP & $\mathrm{A} / 8-13$ & 6 & 0.0535 & Right-handed & Hydrolase (Sulfhydryl Proteinase) \\
\hline 9PAP & A/60-67 & 8 & -0.0304 & Left-handed & Hydrolase (Sulfhydryl Proteinase) \\
\hline 9PAP & $\mathrm{A} / 86-100$ & 15 & 0.0073 & Right-handed & Hydrolase (Sulfhydryl Proteinase) \\
\hline 9PAP & A/138-153 & 14 & 0.1452 & Right-handed & Hydrolase (Sulfhydryl Proteinase) \\
\hline 9PAP & $\mathrm{A} / 175-185$ & 11 & 0.0051 & Right-handed & Hydrolase (Sulfhydryl Proteinase) \\
\hline 9PAP & A/191-198 & 8 & 0.0624 & Right-handed & Hydrolase (Sulfhydryl Proteinase) \\
\hline 9PAP & A/198-203 & 6 & -0.0338 & Left-handed & Hydrolase (Sulfhydryl Proteinase) \\
\hline 1PLC & A/6-13 & 8 & -0.0920 & Left-handed & Electron Transport \\
\hline 1PLC & $\mathrm{A} / 41-55$ & 15 & 0.1393 & Right-handed & Electron Transport \\
\hline 1PLC & $\mathrm{A} / 63-68$ & 6 & 0.0171 & Right-handed & Electron Transport \\
\hline 1PLC & $\mathrm{A} / 84-92$ & 9 & 0.1941 & Right-handed & Electron Transport \\
\hline
\end{tabular}

\section{References}

1. Zhang, S.; Holmes, T.; DiPersio, C.; Hynes, R.O.; Su, X.; Rich, A. Self-complementary oligopeptide matrices support mammalian cell attachment. Biomaterials 1995, 16, 1385-1393. [CrossRef]

2. Boyle, A.L. Applications of de novo designed peptides. In Book Peptide Applications in Biomedicine, Biotechnology and Bioengineering; Elsevier: Amsterdam, The Netherlands, 2018; pp. 51-86. [CrossRef]

3. Ellis-Behnke, R.G.; Liang, Y.-X.; You, S.-W.; Tay, D.K.C.; Zhang, S.; So, K.-F.; Schneider, G.E. Nano neuro knitting: Peptide nanofiber scaffold for brain repair and axon regeneration with functional return of vision. Proc. Natl. Acad. Sci. USA 2006, 103, 5054-5059. [CrossRef] [PubMed]

4. Gelain, F.; Bottai, D.; Vescovi, A.; Zhang, S. Designer Self-Assembling Peptide Nanofiber Scaffolds for Adult Mouse Neural Stem Cell 3-Dimensional Cultures. PLoS ONE 2006, 1, e119. [CrossRef] [PubMed]

5. Welch, J.T.; Kearney, W.R.; Franklin, S.J. Lanthanide-binding helix-turn-helix peptides: Solution structure of a designed metallonuclease. Proc. Natl. Acad. Sci. USA 2003, 100, 3725-3730. [CrossRef]

6. Kovacic, R.T.; Welch, J.T.; Franklin, S.J. Sequence-Selective DNA Cleavage by a Chimeric Metallopeptide. J. Am. Chem. Soc. 2003, 125, 6656-6662. [CrossRef]

7. Reches, M.; Porat, Y.; Gazit, E. Amyloid Fibril Formation by Pentapeptide and Tetrapeptide Fragments of Human Calcitonin. J. Biol. Chem. 2002, 277, 35475-35480. [CrossRef] 
8. Tverdislov, V.A.; Malyshko, E.V. On regularities in the spontaneous formation of structural hierarchies in chiral systems of nonliving and living matter. Phys. Uspekhi 2019, 62, 354-363. [CrossRef]

9. Tverdislov, V.A.; Malyshko, E.V. Chiral Dualism as an Instrument of Hierarchical Structure Formation in Molecular Biology. Symmetry 2020, 12, 587. [CrossRef]

10. Guichard, G.; Benkirane-Jessel, N.; Zeder-Lutz, G.; van Regenmortel, M.H.; Briand, J.P.; Muller, S. Antigenic mimicry of natural L-peptides with retro-inverso-peptidomimetics. Proc. Natl. Acad. Sci. USA 1994, 91, 9765-9769. [CrossRef]

11. Nanda, V.; Andrianarijaona, A.; Narayanan, C. The role of protein homochirality in shaping the energy landscape of folding. Protein Sci. 2007, 16, 1667-1675. [CrossRef] [PubMed]

12. Nagy-Smith, K.; Beltramo, P.; Moore, E.; Tycko, R.; Furst, E.M.; Schneider, J.P. Molecular, Local, and Network-Level Basis for the Enhanced Stiffness of Hydrogel Networks Formed from Coassembled Racemic Peptides: Predictions from Pauling and Corey. ACS Cent. Sci. 2017, 3, 586-597. [CrossRef]

13. McAulay, K.; Dietrich, B.; Su, H.; Scott, M.T.; Rogers, S.; Al-Hilaly, Y.K.; Cui, H.; Serpell, L.C.; Seddon, A.; Draper, E.R.; et al. Using chirality to influence supramolecular gelation. Chem. Sci. 2019, 10, 7801-7806. [CrossRef]

14. Bera, S.; Xue, B.; Rehak, P.; Jacoby, G.; Ji, W.; Shimon, L.J.W.; Beck, R.; Král, P.; Cao, Y.; Gazit, E. Self-Assembly of Aromatic Amino Acid Enantiomers into Supramolecular Materials of High Rigidity. ACS Nano 2020, 14, 1694-1706. [CrossRef]

15. Chen, K.; Sheng, Y.; Wang, J.; Wang, W. Chirality-Dependent Adsorption between Amphipathic Peptide and POPC Membrane. Int. J. Mol. Sci. 2019, 20, 4760. [CrossRef] [PubMed]

16. Qin, M.; Zhang, Y.; Xing, C.; Yang, L.; Zhao, C.; Dou, X.; Feng, C.L. Effect of Stereochemistry on Chirality and Gelation Properties of Supramolecular Self-Assemblies. Chemistry 2021, 27, 3119-3129. [CrossRef]

17. Qing, G.; Zhao, S.; Xiong, Y.; Lv, Z.; Jiang, F.; Liu, Y.; Chen, H.; Zhang, M.; Sun, T. Chiral Effect at Protein/Graphene Interface: A Bioinspired Perspective to Understand Amyloid Formation. J. Am. Chem. Soc. 2014, 136, 10736-10742. [CrossRef] [PubMed]

18. Hou, K.; Zhao, J.; Wang, H.; Li, B.; Li, K.; Shi, X.; Wan, K.; Ai, J.; Lv, J.; Wang, D.; et al. Chiral gold nanoparticles enantioselectively rescue memory deficits in a mouse model of Alzheimer's disease. Nat. Commun. 2020, 11, 4790. [CrossRef]

19. Zheng, Y.; Mao, K.; Chen, S.; Zhu, H. Chirality Effects in Peptide Assembly Structures. Front. Bioeng. Biotechnol. 2021, 9, 703004. [CrossRef] [PubMed]

20. Yao, X.; Hu, Y.; Cao, B.; Peng, R.; Ding, J. Effects of surface molecular chirality on adhesion and differentiation of stem cells. Biomaterials 2013, 34, 9001-9009. [CrossRef] [PubMed]

21. Ma, Y.; Shi, L.; Yue, H.; Gao, X. Recognition at chiral interfaces: From molecules to cells. Colloids Surf. B Biointerfaces 2020, 195, 111268. [CrossRef]

22. Krause, E.; Bienert, M.; Schmieder, P.; Wenschuh, H. The Helix-Destabilizing Propensity Scale of d-Amino Acids: The Influence of Side Chain Steric Effects. J. Am. Chem. Soc. 2000, 122, 4865-4870. [CrossRef]

23. Punitha, V.; Raman, S.S.; Parthasarathi, R.; Subramanian, V.; Rao, J.R.; Nair, B.U.; Ramasami, T. Molecular Dynamics Investigations on the Effect of d Amino Acid Substitution in a Triple-Helix Structure and the Stability of Collagen. J. Phys. Chem. B 2009, 113, 8983-8992. [CrossRef] [PubMed]

24. Zheng, Y.; Yu, L.; Zou, Y.; Yang, Y.; Wang, C. Steric Dependence of Chirality Effect in Surface-Mediated Peptide Assemblies Identified with Scanning Tunneling Microscopy. Nano Lett. 2019, 19, 5403-5409. [CrossRef]

25. Fairman, R.; Anthony-Cahill, S.J.; DeGrado, W.F. The helix-forming propensity of D-alanine in a right-handed. alpha.-helix. J. Am. Chem. Soc. 1992, 114, 5458-5459. [CrossRef]

26. Hu, K.; Jiang, Y.; Xiong, W.; Li, H.; Zhang, P.-Y.; Yin, F.; Zhang, Q.; Geng, H.; Jiang, F.; Li, Z.; et al. Tuning peptide self-assembly by an in-tether chiral center. Sci. Adv. 2018, 4, eaar5907. [CrossRef]

27. Hu, K.; Geng, H.; Zhang, Q.; Liu, Q.; Xie, M.; Sun, C.; Li, W.; Lin, H.; Jiang, F.; Wang, T.; et al. An In-tether Chiral Center Modulates the Helicity, Cell Permeability, and Target Binding Affinity of a Peptide. Angew. Chem. 2016, 128, 8145-8149. [CrossRef]

28. Gil, A.M.; Casanovas, J.; Mayans, E.; Jiménez, A.I.; Puiggalí, J.; Alemán, C. Heterochirality Restricts the Self-Assembly of Phenylalanine Dipeptides Capped with Highly Aromatic Groups. J. Phys. Chem. B 2020, 124, 5913-5918. [CrossRef]

29. Kralj, S.; Bellotto, O.; Parisi, E.; Garcia, A.M.; Iglesias, D.; Semeraro, S.; Deganutti, C.; D’Andrea, P.; Vargiu, A.V.; Geremia, S.; et al. Heterochirality and Halogenation Control Phe-Phe Hierarchical Assembly. ACS Nano 2020, 14, 16951-16961. [CrossRef]

30. Zhang, G.; Zhang, L.; Rao, H.; Wang, Y.; Li, Q.; Qi, W.; Yang, X.; Su, R.; He, Z. Role of molecular chirality and solvents in directing the self-assembly of peptide into an ultra-pH-sensitive hydrogel. J. Colloid Interface Sci. 2020, 577, 388-396. [CrossRef]

31. Adzhubei, A.A.; Sternberg, M.; Makarov, A.A. Polyproline-II Helix in Proteins: Structure and Function. J. Mol. Biol. 2013, 425, 2100-2132. [CrossRef] [PubMed]

32. Zarrinpar, A.; Bhattacharyya, R.P.; Lim, W.A. The structure and function of proline recognition domains. Sci. STKE 2003, 179 , re8. [CrossRef] [PubMed]

33. Platé, N.A.; Shibaev, V.P. Comb-Shaped Polymers and Liquid Crystals; Springer: Boston, MA, USA, 2012. [CrossRef]

34. Livolant, F.; Leforestier, A. Condensed phases of DNA: Structures and phase transitions. Prog. Polym. Sci. 1996, 21, 1115-1164. [CrossRef]

35. Chakraborty, D.; Mugnai, M.; Thirumalai, D. On the Emergence of Orientational Order in Folded Proteins with Implications for Allostery. Symmetry 2021, 13, 770. [CrossRef]

36. Sidorova, A.E.; Levashova, N.T.; Malyshko, E.; Tverdislov, V. Autowave Self-Organization in the Folding of Proteins. Mosc. Univ. Phys. Bull. 2019, 74, 213-226. [CrossRef] 
37. Abrusán, G.; Marsh, J.A. Alpha Helices Are More Robust to Mutations than Beta Strands. PLoS Comput. Biol. 2016, 12 , e1005242. [CrossRef]

38. Pauling, L.; Corey, R.B. The Pleated Sheet, A New Layer Configuration of Polypeptide Chains. Proc. Natl. Acad. Sci. USA 1951, 37, 2451-2456. [CrossRef]

39. Tonlolo, C.; Benedetti, E. The polypeptide 310-helix. Trends Biochem. Sci. 1991, 16, 350-353. [CrossRef]

40. Kendrew, J.C.; Bodo, G.; Dintzis, H.M.; Parrish, R.G.; Wyckoff, H.; Phillips, D.C. A Three-Dimensional Model of the Myoglobin Molecule Obtained by X-Ray Analysis. Nature 1958, 181, 662-666. [CrossRef]

41. Armen, R.; Alonso, D.O.; Daggett, V. The role of $\alpha-, 310-$, and $\pi$-helix in helix $\rightarrow$ coil transitions. Protein Sci. 2003, $12,1145-1157$. [CrossRef]

42. Cooley, R.B.; Arp, D.J.; Karplus, P.A. Evolutionary Origin of a Secondary Structure: $\pi$-Helices as Cryptic but Widespread Insertional Variations of $\alpha$-Helices That Enhance Protein Functionality. J. Mol. Biol. 2010, 404, 232-246. [CrossRef]

43. Dasgupta, B.; Chakrabarti, P. pi-Turns: Types, systematics and the context of their occurrence in protein structures. BMC Struct. Biol. 2008, 8, 39. [CrossRef]

44. Fodje, M.; Al-Karadaghi, S. Occurrence, conformational features and amino acid propensities for the $\pi$-helix. Protein Eng. Des. Sel. 2002, 15, 353-358. [CrossRef] [PubMed]

45. Religa, T.L.; Johnson, C.M.; Vu, D.; Brewer, S.H.; Dyer, R.B.; Fersht, A.R. The helix turn helix motif as an ultrafast independently folding domain: The pathway of folding of Engrailed homeodomain. Proc. Natl. Acad. Sci. USA 2007, 104, 9272-9277. [CrossRef] [PubMed]

46. Pavone, V.; Gaeta, G.; Lombardi, A.; Nastri, F.; Maglio, O.; Isernia, C.; Saviano, M. Discovering protein secondary structures: Classification and description of isolated $\alpha$-turns. Biopolymers 1996, 38, 705-721. [CrossRef]

47. Hutchinson, E.G.; Thornton, J. A revised set of potentials for beta-turn formation in proteins. Protein Sci. 1994, 3, $2207-2216$. [CrossRef]

48. Donate, L.E.; Rufino, S.D.; Canard, L.H.; Blundell, T.L. Conformational analysis and clustering of short and medium size loops connecting regular secondary structures: A database for modeling and prediction. Protein Sci. 1996, 5, 2600-2616. [CrossRef] [PubMed]

49. Joo, H.; Chavan, A.G.; Fraga, K.J.; Tsai, J. An amino acid code for irregular and mixed protein packing. Proteins 2015, 83, $2147-2161$. [CrossRef]

50. Rose, G.D.; Glerasch, L.M.; Smith, J.A. Turns in Peptides and Proteins. Adv. Protein Chem. 1985, 37, 1-109. [CrossRef]

51. Marcelino, A.M.C.; Gierasch, L.M. Roles of $\beta$-turns in protein folding: From peptide models to protein engineering. Biopolymers 2008, 89, 380-391. [CrossRef] [PubMed]

52. Koch, O.; Klebe, G. Turns revisited: A uniform and comprehensive classification of normal, open, and reverse turn families minimizing unassigned random chain portions. Proteins Struct. Funct. Bioinform. 2009, 74, 353-367. [CrossRef] [PubMed]

53. Kabsch, W.; Sander, C. Dictionary of protein secondary structure: Pattern recognition of hydrogen-bonded and geometrical features. Biopolymers 1983, 22, 2577-2637. [CrossRef] [PubMed]

54. Munoz, V.; Henry, E.; Hofrichter, J.; Eaton, W.A. A statistical mechanical model for $\beta$-hairpin kinetics. Proc. Natl. Acad. Sci. USA 1998, 95, 5872-5879. [CrossRef]

55. Dasgupta, B.; Pal, L.; Basu, G.; Chakrabarti, P. Expanded turn conformations: Characterization and sequence-structure correspondence in $\alpha$-turns with implications in helix folding. Proteins Struct. Funct. Bioinform. 2004, 55, 305-315. [CrossRef] [PubMed]

56. Skipper, L. Proteins. Overview. In Encyclopedia of Analytical Science; Elsevier: Amsterdam, The Netherlands, 2005 ; pp. 344-352. [CrossRef]

57. Leszczynski, J.F.; Rose, G.D. Loops in Globular Proteins: A Novel Category of Secondary Structure. Science 1986, 234, 849-855. [CrossRef]

58. Wang, X.; Wang, M.; Tong, Y.; Shan, L.; Wang, J. Probing the folding capacity and residual structures in 1-79 residues fragment of staphylococcal nuclease by biophysical and NMR methods. Biochimie 2006, 88, 1343-1355. [CrossRef]

59. Neuhaus, F.C. Role of the omega loop in specificity determination in subsite 2 of the D-alanine:D-alanine (D-lactate) ligase from Leuconostoc mesenteroides: A molecular docking study. J. Mol. Graph. Model. 2011, 30, 31-37. [CrossRef] [PubMed]

60. Likhachev, I.; Bystrov, V. Assembly of a phenylalanine nanotube with a molecular dynamic manipulator. Math. Biol. Bioinform. 2021, 16, 244-255. [CrossRef]

61. Zelenovskiy, P.S.; Nuraeva, A.; Kopyl, S.; Arkhipov, S.G.; Vasilev, S.G.; Bystrov, V.S.; Gruzdev, D.A.; Waliczek, M.; Svitlyk, V.; Shur, V.Y.; et al. Chirality-Dependent Growth of Self-Assembled Diphenylalanine Microtubes. Cryst. Growth Des. 2019, 19, 6414-6421. [CrossRef]

62. Bystrov, V.S.; Zelenovskiy, P.; Nuraeva, A.; Kopyl, S.; Zhulyabina, O.A.; Tverdislov, V. Molecular modeling and computational study of the chiral-dependent structures and properties of self-assembling diphenylalanine peptide nanotubes. J. Mol. Model. 2019, 25, 199. [CrossRef] [PubMed]

63. Bystrov, V.; Coutinho, J.; Zelenovskiy, P.; Nuraeva, A.; Kopyl, S.; Zhulyabina, O.; Tverdislov, V. Structures and Properties of the Self-Assembling Diphenylalanine Peptide Nanotubes Containing Water Molecules: Modeling and Data Analysis. Nanomaterials 2020, 10, 1999. [CrossRef] 
64. German, H.W.; Uyaver, S.; Hansmann, A.U.H.E. Self-Assembly of Phenylalanine-Based Molecules. J. Phys. Chem. A 2015, 119, 1609-1615. [CrossRef] [PubMed]

65. Adler-Abramovich, L.; Vaks, L.; Carny, O.; Trudler, D.; Magno, A.; Caflisch, A.; Frenkel, D.; Gazit, E. Phenylalanine assembly into toxic fibrils suggests amyloid etiology in phenylketonuria. Nat. Chem. Biol. 2012, 8, 701-706. [CrossRef] [PubMed]

66. Bystrov, V.; Sidorova, A.; Lutsenko, A.; Shpigun, D.; Malyshko, E.; Nuraeva, A.; Zelenovskiy, P.; Kopyl, S.; Kholkin, A. Modeling of Self-Assembled Peptide Nanotubes and Determination of Their Chirality Sign Based on Dipole Moment Calculations. Nanomaterials 2021, 11, 2415. [CrossRef]

67. Petitjean, M. On the root mean square quantitative chirality and quantitative symmetry measures. J. Math. Phys. 1999, 40, 4587-4595. [CrossRef]

68. Peng, X.-L.; Fang, K.-T.; Hu, Q.-N.; Liang, Y.-Z. Impersonality of the Connectivity Index and Recomposition of Topological Indices According to Different Properties. Molecules 2004, 9, 1089-1099. [CrossRef]

69. Yaffe, D.; Cohen, Y. Neural Network Based Temperature-Dependent Quantitative Structure Property Relations (QSPRs) for Predicting Vapor Pressure of Hydrocarbons. J. Chem. Inf. Comput. Sci. 2001, 41, 463-477. [CrossRef]

70. McClelland, H.E.; Jurs, P.C. Quantitative Structure-Property Relationships for the Prediction of Vapor Pressures of Organic Compounds from Molecular Structures. J. Chem. Inf. Comput. Sci. 2000, 40, 967-975. [CrossRef]

71. Zhao, T.; Zhang, Q.; Long, H.; Xu, L. Graph Theoretical Representation of Atomic Asymmetry and Molecular Chirality of Benzenoids in Two-Dimensional Space. PLoS ONE 2014, 9, e102043. [CrossRef] [PubMed]

72. Mezey, P.G. The proof of the metric properties of a fuzzy chirality measure of molecular electron density clouds. J. Mol. Struct. Theochem 1998, 455, 183-190. [CrossRef]

73. Gilat, G.; Schulman, L. Chiral interaction, magnitude of the effects and application to natural selection of L-enantiomer. Chem. Phys. Lett. 1985, 121, 13-16. [CrossRef]

74. Zabrodsky, H.; Peleg, S.; Avnir, D. Continuous symmetry measures. J. Am. Chem. Soc. 1992, 114, 7843-7851. [CrossRef]

75. Pinsky, M.; Dryzun, C.; Casanova, D.; Alemany, P.; Avnir, D. Analytical methods for calculating Continuous Symmetry Measures and the Chirality Measure. J. Comput. Chem. 2008, 29, 2712-2721. [CrossRef] [PubMed]

76. Luzanov, A.V.; Nerukh, D. Simple One-electron Invariants of Molecular Chirality. J. Math. Chem. 2006, 41, 417-435. [CrossRef]

77. Raos, G. Degrees of Chirality in Helical Structures. Macromol. Theory Simul. 2002, 11, 739-750. [CrossRef]

78. Ramachandran, G.; Ramakrishnan, C.; Sasisekharan, V. Stereochemistry of polypeptide chain configurations. J. Mol. Biol. 1963, 7, 95-99. [CrossRef]

79. Baruch-Shpigler, Y.; Wang, H.; Tuvi-Arad, I.; Avnir, D. Chiral Ramachandran Plots I: Glycine. Biochemistry 2017, 56, 5635-5643. [CrossRef]

80. Wang, H.; Avnir, D.; Tuvi-Arad, I. Chiral Ramachandran Plots II: General Trends and Protein Chirality Spectra. Biochemistry 2018, 57, 6395-6403. [CrossRef] [PubMed]

81. Mannige, R.V. An exhaustive survey of regular peptide conformations using a new metric for backbone handedness (h). PeerJ 2017, 5, 3327. [CrossRef]

82. Robinson, S.W.; Afzal, A.M.; Leader, D.P. Bioinformatics: Concepts, Methods, and Data. In Handbook of Pharmacogenomics and Stratified Medicine, 1st ed.; Padmanabhan, S., Ed.; Academic Press: New York, NY, USA, 2014; pp. $259-287$.

83. Johansson, M.U.; Zoete, V.; Michielin, O.; Guex, N. Defining and searching for structural motifs using DeepView/SwissPdbViewer. BMC Bioinform. 2012, 13, 173. [CrossRef]

84. Richardson, J.S. The anatomy and taxonomy of protein structure. Adv. Protein Chem. 1981, 34, 167-339. [CrossRef]

85. Lewis, P.N.; Momany, F.A.; Scheraga, H.A. Energy Parameters in Polypeptides. VI. Conformational Energy Analysis of the N-Acetyl N'-Methyl Amides of the Twenty Naturally Occurring Amino Acids. Isr. J. Chem. 1973, 11, 121-152. [CrossRef]

86. Wilmot, C.; Thornton, J. Analysis and prediction of the different types of $\beta$-turn in proteins. J. Mol. Biol. 1988, 203, 221-232. [CrossRef]

87. De Brevern, A.G. Extension of the classical classification of $\beta$-turns. Sci. Rep. 2016, 6, 33191. [CrossRef] [PubMed]

88. Ting, D.; Wang, G.; Shapovalov, M.; Mitra, R.; Jordan, M.; Dunbrack, R.L. Neighbor-Dependent Ramachandran Probability Distributions of Amino Acids Developed from a Hierarchical Dirichlet Process Model. PLoS Comput. Biol. 2010, 6, e1000763. [CrossRef]

89. Shapovalov, M.; Slobodan, V.; Dunbrack, R.L. A new clustering and nomenclature for beta turns derived from high-resolution protein structures. PLoS Comput. Biol. 2019, 15, e1006844. [CrossRef]

90. Fang, C.; Shang, Y.; Xu, N. Improving Protein Gamma-Turn Prediction Using Inception Capsule Networks. Sci. Rep. 2018, 8, 15741. [CrossRef]

91. Fiser, A.; Do, R.K.G.; Šali, A. Modeling of loops in protein structures. Protein Sci. 2000, 9, 1753-1773. [CrossRef] [PubMed]

92. Duddy, W.J.; Nissink, J.W.M.; Allen, F.H.; Milner-White, E.J. Mimicry by asx- and ST-turns of the four main types of $\beta$-turn in proteins. Protein Sci. 2008, 13, 3051-3055. [CrossRef]

93. Eswar, N.; Ramakrishnan, C. Secondary structures without backbone: An analysis of backbone mimicry by polar side chains in protein structures. Protein Eng. Des. Sel. 1999, 12, 447-455. [CrossRef]

94. Sidorova, A.E.; Lutsenko, A.O.; Shpigun, D.K.; Malyshko, E.V.; Tverdislov, V.A. Methods to Determine the Chirality Sign for Helical and Superhelical Protein Structures. Biophysics 2021, 66, 357-363. [CrossRef] 
95. Sidorova, A.; Malyshko, E.; Lutsenko, A.; Shpigun, D.; Bagrova, O. Protein Helical Structures: Defining Handedness and Localization Features. Symmetry 2021, 13, 879. [CrossRef]

96. Nicholson, H.; Anderson, D.E.; Pin, S.D.; Matthews, B.W. Analysis of the interaction between charged side chains and the.alpha.helix dipole using designed thermostable mutants of phage T4 lysozyme. Biochemistry 1991, 30, 9816-9828. [CrossRef]

97. Ludwig, M.L.; Pattridge, K.A.; Metzger, A.L.; Dixon, M.M.; Eren, M.; Feng, Y.; Swenson, R.P. Control of Oxidation-Reduction Potentials in Flavodoxin from Clostridium beijerinckii: The Role of Conformation Changes. Biochemistry 1997, 36, 1259-1280. [CrossRef] [PubMed]

98. Nataraj, D.V.; Srinivasan, N.; Sowdhamini, R.; Ramakrishnan, C. $\alpha$-Turns in protein structure. Curr. Sci. 1995, $69,434-447$.

99. Taylor, N.R.; Cleasby, A.; Singh, O.; Skarzynski, T.; Wonacott, A.J.; Smith, P.W.; Sollis, S.L.; Howes, P.D.; Cherry, P.C.; Bethell, R.; et al. Dihydropyrancarboxamides Related to Zanamivir: A New Series of Inhibitors of Influenza Virus Sialidases. 2. Crystallographic and Molecular Modeling Study of Complexes of 4-Amino-4H-pyran-6-carboxamides and Sialidase from Influenza Virus Types A and B. J. Med. Chem. 1998, 41, 798-807. [CrossRef] [PubMed]

100. Baker, E.; Dodson, E.J. Crystallographic refinement of the structure of actinidin at $1.7 \AA$ resolution by fast Fourier least-squares methods. Acta Crystallogr. 1980, A36, 559-572. [CrossRef]

101. Likhachev, I.V.; Balabaev, N.K.; Galzitskaya, O.V. Elastic and Non-elastic Properties of Cadherin Ectodomain: Comparison with Mechanical System. Adv. Intell. Syst. Comput. 2019, 938, 555-566. [CrossRef]

102. Glyakina, A.V.; Likhachev, I.V.; Balabaev, N.K.; Galzitskaya, O.V. Comparative mechanical unfolding studies of spectrin domains R15, R16 and R17. J. Struct. Biol. 2018, 201, 162-170. [CrossRef]

103. Lemak, A.S.; Balabaev, N.K. A Comparison Between Collisional Dynamics and Brownian Dynamics. Mol. Simul. 1995, 15, 223-231. [CrossRef]

104. Lemak, A.S.; Balabaev, N.K. Molecular dynamics simulation of a polymer chain in solution by collisional dynamics method. J. Comput. Chem. 1996, 17, 1685-1695. [CrossRef]

105. HyperChem Download-Sophisticated Molecular Modeling Environment. Available online: https://hyperchem.software. informer.com/ (accessed on 21 October 2021).

106. Rocha, G.B.; Freire, R.O.; Simas, A.M.; Stewart, J.J.P. RM1: A reparameterization of AM1 for H, C, N, O, P, S, F, Cl, Br, and I. J Comput. Chem. 2006, 27, 1101-1111. [CrossRef] [PubMed]

107. The Protein Data Bank. Available online: http://www.rcsb.org/ (accessed on 1 October 2020).

108. Bystrov, V.S.; Kopyl, S.A.; Zelenovskiy, P.; Zhulyabina, O.A.; Tverdislov, V.; Salehli, F.; Ghermani, N.E.; Shur, V.; Kholkin, A.L. Investigation of physical properties of diphenylalanine peptide nanotubes having different chiralities and embedded water molecules. Ferroelectrics 2018, 525, 168-177. [CrossRef] 